COGNITIVE

NEUROSCIENCE
Citation: Malashichev, Y. and Robins, A 2018. Lateralized motor responses in anuran amphibians - an overview of methods and perspectives of studies Bio. Comm. 63(4): 210-242. https://doi. org/10.21638/spbu03.2018.402

Author's information: Yegor Malashichev PhD, Associate Professor, orcid.org/00000003-3813-5712; Andrew Robins, B.Sc (Hons), PhD, orcid.org/0000-0001-7806-8409

Manuscript Editor: Alla Ignashchenkova, Universitatsklinikum Tubingen, Eberhard Karls Universitat Tubingen, Tubingen, Germany

Received: December 10, 2018;

Revised: December 28, 2018;

Accepted: January 21, 2019;

Copyright: @ 2018 Malashichev and Robins. This is an open-access article distributed under the terms of the License Agreement with Saint Petersburg State University, which permits to the authors unrestricted distribution, and self-archiving free of charge.

Funding: This work was supported by the Russian Science Foundation (Grant No. 14-14-00284).

Competing interests: The authors have declared that no competing interests exist.

\section{Lateralized motor responses in anuran amphibians - an overview of methods and perspectives of studies}

\author{
Yegor Malashichev ${ }^{1,2}$ and Andrew Robins ${ }^{3}$ \\ ${ }^{1}$ Department of Vertebrate Zoology, Faculty of Biology, Saint Petersburg State University, \\ Universitetskaya nab., 7-9, Saint Petersburg, 199034, Russian Federation \\ ${ }^{2}$ Laboratory of Molecular Neurobiology, Department of Ecological Physiology, \\ Institute of Experimental Medicine, ul. Akad. Pavlova, 12, Saint Petersburg, 197376, \\ Russian Federation \\ ${ }^{3}$ Centre for Animal Welfare and Ethics, School of Veterinary Science, \\ University of Queensland, Gatton, Australia
}

Address correspondence and requests for materials to Andrew Robins, andyrobins1@gmail.com

\begin{abstract}
Anuran amphibians represent the most usual subjects for experimental biological research and a divergent group of extant vertebrates comprising species adapted to a variety of environments from aquatic to arboreal. Thus, they become excellent models in research of motor lateralization due to their different phylogenetic position and their anatomical and ecological diversity throughout their evolutionary history, as well as variety of locomotive habits and a diversity of limb use during walking, swimming, feeding and other activities. From the first works in mid-1990's to the present day, a noticeable progress, a noticeable progress in the study of motor lateralization in anurans is made favored by a set of methodological approaches and their application to various species and life stages. Together, these advances foretell a plethora of interesting developments in the world of laterality research with the anuran amphibian model. Here, the discovery of right-pawedness in toads through the development of a set of different techniques to assess motor lateralization in anuran amphibians, and, as a consequence - important results revealing behavioral and morphological correlates are reviewed and discussed in evolutionary and eco-morphological perspective.
\end{abstract}

Keywords: anuran amphibians, lateralization, motor asymmetries, C-start, tadpoles, frogs, snout-wiping response, righting response, asynchronous locomotion, evolution of motor skills.

\section{Introduction}

Motor lateralization has been studied to date in a range of anuran species belonging to different families. There were a number of earlier reports suggesting limb preference in anurans at least at individual or even population level (Singh, 1971; Dill, 1977; Adler and Taylor, 1981; Borkhvardt and Ivashintsova, 1995). Initially, authors considered possible links between the asymmetric skeletal morphology (length and weight of the long bones or shoulder girdle structure), musculature strength, and limb preference. However, only Dill's (1977) work presented both morphological and behavioural data, but found no significant correlation between the proportion of left jumps in Hyla regilla to avoid a predator model and asymmetry in long bones in the hindlimbs. The proposition by Borkhvardt and Ivashintsova (1995) that the asymmetric morphology of the shoulder girdle found in the vast majority of frogs and salamanders may be affected by the differential contraction of developing muscles on contralateral sides of the body due to 
handedness in larvae has also been discounted as a correlate to motor lateralization (Malashichev, 2002; Robins and Rogers, 2002).

Interesting observations of motor lateralization were made by Adler and Taylor (1981) on Rana clamitans trained in a circular arena to seek a peripherally positioned goalbox located $90^{\circ}$ anticlockwise from the peripheral lamp. The relative position of the lamp and a goalbox was always fixed, while the position of the lamp in respect to the orientation of the frog in the centre of the arena and positions of false boxes changed from trial to trial. Individual frogs revealed significant handedness to turn right first when searching the goalbox, while others had no preferences. The tendency of turning preferences were found significant in the group with almost exactly double prevalence of the right turns (44 left, 82 right; $G=10.96,1 \mathrm{df} ; p<0.05$ ). While smaller frogs were apparently random in their directional preference, larger frogs were more consistent in their turning preferences and the most interesting relationship was the tendency for them to move in right-handed spirals in the arena from its centre to periphery. It remains uncertain whether the tendency to turn right would exist in an untrained population. Moreover, this behavioural lateralization may reflect lateralized visual processing instead of lateralized motor functions. That is, a left-eye bias to search for escape routes from the arena, using right-hemisphere spatial-analysis functions (Bianki, 1981), may be a contributing factor to the behavioural lateralization observed. Indeed, as early as in 1963 Bianki reported asymmetry of electric response in contralateral visual centres in the midbrain - the tegmentum mesencephali, a major site of multisensory integration with descending pathways to the premotor-motor systems in the brain stem (Ingle, 1976; Ewert, 1980; Gaillard, 1990) - of Grass frogs, Rana temporaria, which was dependent on the position of the lamp indicating a link between the spatial analysis and the asymmetric activation in the brain hemispheres (Bianki, 1963).

The previous examples illustrate a major difficulty faced by researchers when interpreting the causal factors for a given behaviour. Indeed, many reports of motor lateralization (i.e., "handedness") in primates are actually forms of visual or visuomotor lateralization, since the tasks are visually guided (Fernand, 1987; Andrew, Tommasi, and Ford, 2000). Throughout this review we restrict our discussion to motor behaviours with limited or no obvious involvement of the visual system, in an effort to isolate any lateralization in the motor system from other sensory inputs.

Infrequent studies using diverse methods characterised the research into motor lateralization in anurans prior to the findings of limb preferences in Bufo toads (Bisazza et al., 1996, 1997). Now, recognition of the wide ecological and behavioural adaptation of anurans to di- verse environments allows links to be tested between lateralized motor responses with existing morphologies, locomotive modes or phylogenetic position. A number of standardized experimental protocols described below have been applied to a quite different species. Even with a comparatively restricted list of them tested there are already striking patterns emerging regarding motor lateralization, evolutionary specializations and developmental stages of life. The data on non-visual motor turning responses in anuran larvae will first be considered before a discussion of snout-wiping experiments in the adults, whereby an animal is required to remove an obstacle from its snout using one or both of the forelimbs. The review continues with a more intensive discussion of lateralization of righting responses, a postural reflex predominantly involving either forelimbs or hindlimbs. In the end of this review we provide a model of interaction between motor asymmetries, preferred mode of locomotion, frog morphotypes and ecological specialization of the studied anuran species. An overall discussion of neural organization in the anuran motor system and speculations on the classification of the lateralized motor responses and their neural control is provided in the final section of the revew.

\section{Tadpoles turning (non-visual responses)}

As early as tadpoles, anuran amphibians, as well as larval salamanders, not only possess visual lateralization (Bisazza, De Santi, Bonso, and Sovrano, 2002; Izvekov et al., 2018), but also possess lateralization in the neural control of movements, apparent across a range of specific behaviours. Tadpoles air-breathe to supplement their aquatic respiration by vertically ascending towards and breaking the water surface, then rapidly turning to descend in a vertical direction (Wassersug, Naitoh, and Yamashita, 1999). They can also avoid predators or turn when startled by an irritant (sudden change in lighting, pressure waves, etc.) using the same rapid response illustrated by a series of video frames in Fig. 1 (Yamashita, Naitoh, and Wassersug, 2000). This rapid turning of the body to one side, the C-start, has been found preferentially directed to the left in majority of tadpole anurans. Alternatively, tadpoles can change the swimming direction by slow side turning (Wassersug and Yamashita, 2002). In the latter instance, however, the direction of turnings might not be necessarily lateralized. Tadpoles from a range of anuran species have been scored for turning preferences under laboratory conditions, revealing motor lateralizations that are dependent on the tadpole's stage of development. Anuran amphibians were usually collected from natural populations (except the laboratory-bred Bombina orientalis and Xenopus laevis) and scored during the latter half of their pre-metamorphic life, when they live in a form of free swimming 

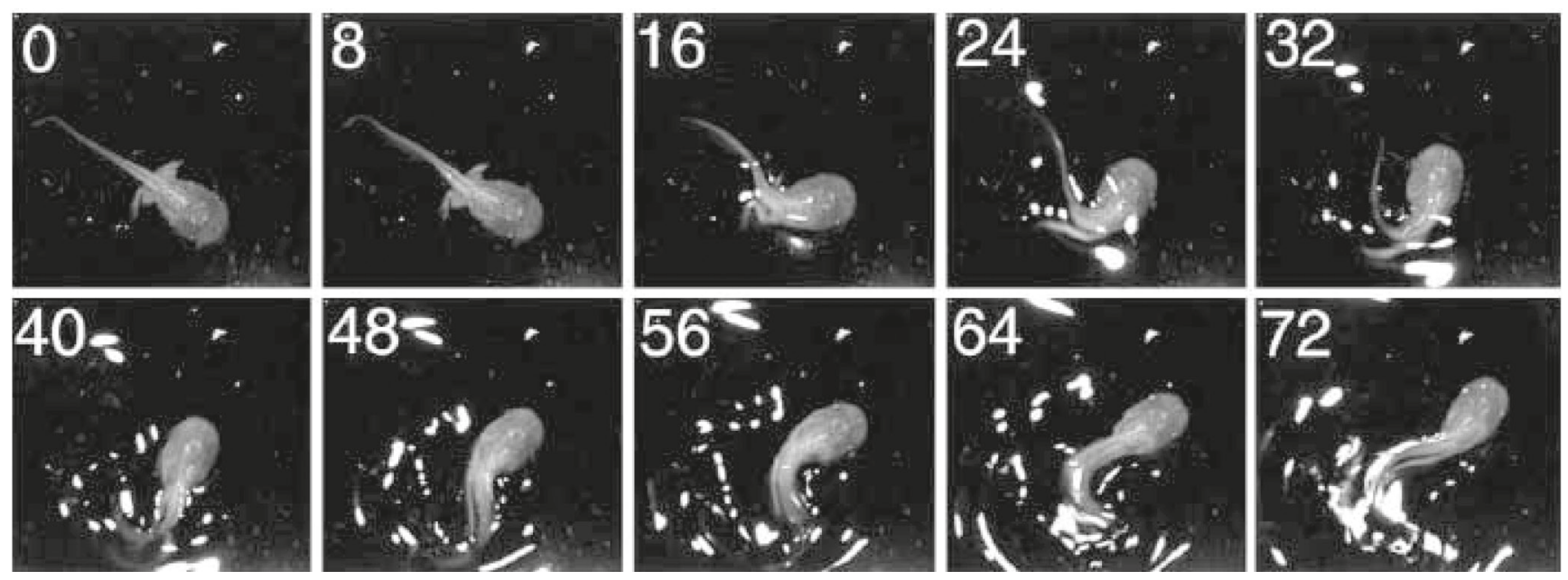

Fig. 1. The startle response of a Microhyla ornata larva (C-start turning) induced by a mechanical pulse delivered to the bottom of its container, filmed from above. The number in each sequence frame indicates elapsed time in ms. This tadpole responded to the stimulus by an initial

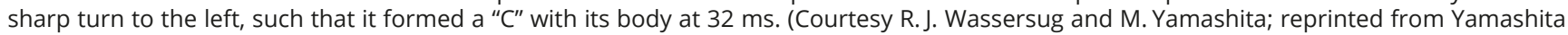
et al., 2000.)

larvae after hatching from egg membranes (i.e., developmental stages 25 onwards (Gosner, 1960)). In majority of species studied the rapid turns followed by startle conditions or after surfacing to breath air were put on trial (summarised in Fig. 2).

Rana catesbeiana tadpoles were found to have an overall preference to turn to the left in $65 \%$ of cases when descending from the surface, although this preference was non-significant in very early tadpoles (see Fig. 2) and, probably, in older tadpoles after Gosner stage 41 (Wassersug, Naitoh, and Yamashita, 1999). Similarly, Rana sylvatica tadpoles between Gosner stages 25 and 35 were found to turn preferentially left, but after stage 35 (approaching metamorphosis), when hindlimbs start to develop and tadpoles became progressively more dependent on limb movements for swimming, the preference became again non-significant (Oseen, Newhook, and Wassersug, 2001). These findings are in general agreement with observations on a few other species. Lateralization of turning after surfacing to breathe air was found in a number of hylid species such as Litoria latopalmata (Rogers, 2002), Hyla andina, and Scinax nasius, but was not found in Phrynohyas venulosa in a group of slightly older tadpoles (Wassersug and Yamashita, 2002). Tadpoles of two other species, X. laevis and B. orientalis, exhibit no turning preferences at any Gosner developmental stage studied: the former - between stages 25 and 42 (Wassersug, Naitoh, and Yamashita, 1999) and the latter - between stages 32 and 41 (Goree and Wassersug, 2001).

Leftwards-turning preferences have also been found in Microhyla ornata (Microhylidae), using a different testing procedure (Yamashita, Naitoh, and Wassersug, 2000). The startle turns in individual tadpoles were scored in response to a sudden pressure (shock) wave generated through the floor of the shallow watch glass. Although horizontal turning responses were scored, in contrast to the vertical turning responses scored in the studies discussed above, the turning bias was $65 \%$ to the left in M. ornata between Gosner development stages 26 and 41 . This was similar in preference to the earlier findings made with R.catesbeiana when descending after air breathing over the same period of development (Wassersug, Naitoh, and Yamashita, 1999; Yamashita, Naitoh, and Wassersug, 2000). No turning preferences were found in M. ornata tadpoles beyond the 42 stage of development (Yamashita, Naitoh, and Wassersug, 2000). In contrast, tadpoles of one species, Bufo japonicus, revealed no turning preference in its startle response at any time of their development between Gosner stages 24 and 42 (Wassersug and Yamashita, 2002).

This comparison of the two experimental protocols (i.e., descending after air breathing and startle responses to shock waves) leads to a conclusion that both ways of assessment of lateralization in tadpole turning deal with the same behaviour - rapid C-start turning (Fig. 1; see also Wassersug and Yamashita 2002 for deeper discussion). The observed behavioural responses are most probably related to asymmetry in the system of giant Mauthner neurons (M-cells), which operate the abrupt contraction of axial muscles, as they do in fish (Vallortigara and Bisazza, 2002; Wassersug and Yamashita, 2002). This system was better described in fish and usually consists of two cells in the hindbrain and sometimes a series of homologs (Fetcho and Faber, 1988; Fetcho, 1990, 1991, 1992). The spinal motor neurons that receive input from Mauthner cells in larval amphibians are the earliest to develop (Blight, 1978; Nordlander, Baden, and Ryba, 1985). The Mauthner cell system seems to be lateralized in anuran (Wassersug and Yamashita, 2002) as well as in 


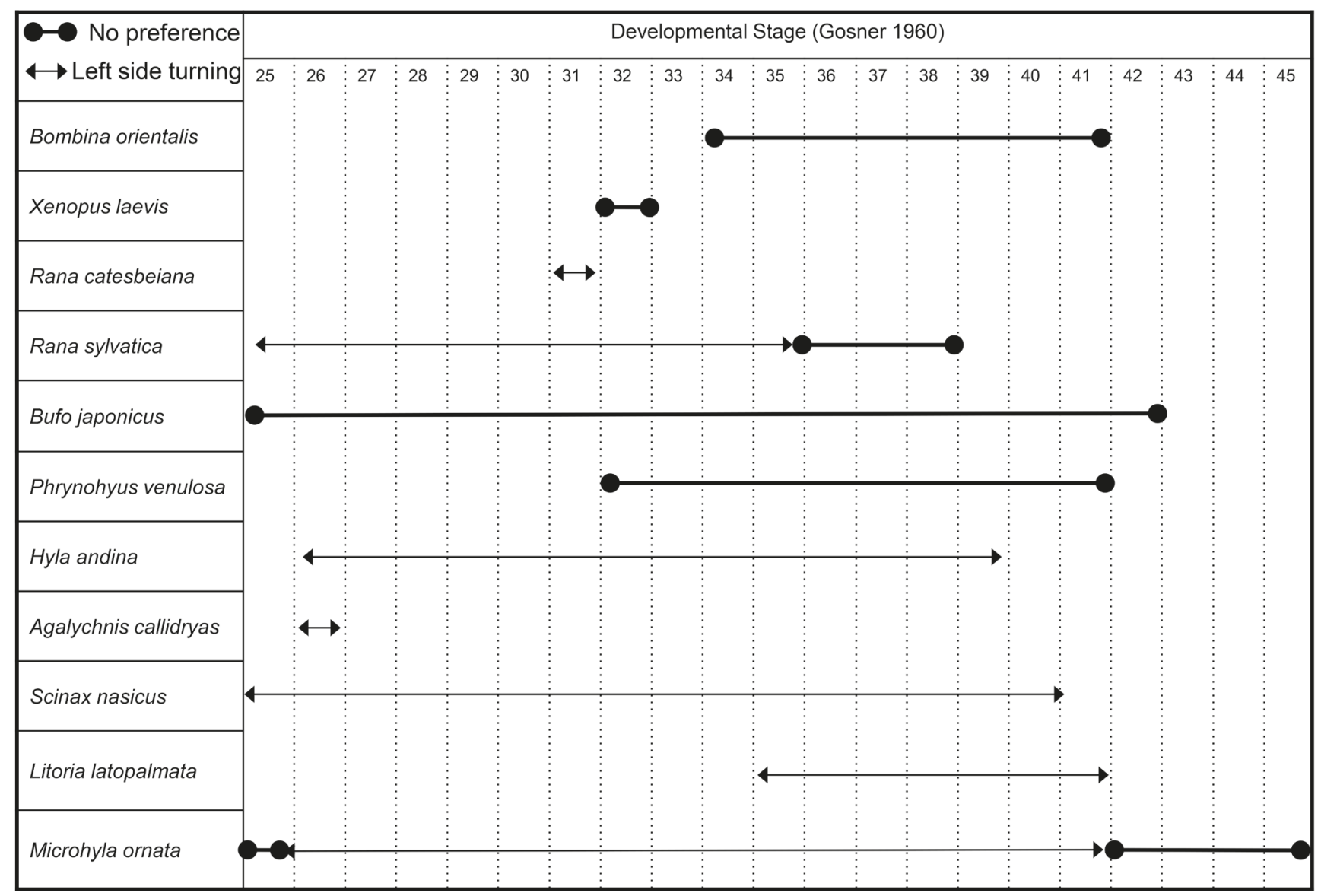

Fig. 2. Summary of the found left-sided preference in C-start escape turns in larvae of different anuran species . Note that some species have no lateralization of the startle response, while those, which have, lack this lateralization at later developmental stages prior to metamorphosis. Gosner stage 25 (Gosner, 1960) is the stage of early free swimming and feeding larvae after full yolk resorbtion. Approximately at stage 33 the hindlimbs became easily visible in tadpoles, while after stage 37 they are already so well developed and the tail is beginning to reduce that hindlimbs play progressively greater role in tadpole locomotion. At stages $44-45$ young postmetamorphs usually leave the water. Data from: Rana catesbeiana, X. Iaevis (Wassersug, Naitoh, and Yamashita, 1999), Rana sylvatica (Oseen, Newhook, and Wassersug, 2001), Bombina orientalis (Goree and Wassersug, 2001), Bufo japonicas, Phrynohyas venulosa, Hyla andina, Scinax nasicus, (Wassersug and Yamashita, 2002), Litoria latopalmata (Rogers, 2002), Microhyla ornata (Yamashita, Naitoh, and Wassersug, 2000), Agalychnis callidryas (Briggs-Gonzales and Gonzalez, 2016).

caudate (Izvekov et al., 2018) amphibians and in all species it leads to the tadpole turning directed preferentially to the left. Wassersug and Yamashita (2002) further proposed a model, which predicts that the morphological asymmetry in M-cells might be responsible for lateralized behaviours in anuran larvae. If M-cell asymmetry is indeed the basis for lateralized turning in tadpoles then, as the theory predicts, a clear correspondence between the amount of morphological and behavioural asymmetry should be found.

Importantly, C-start turning preferences in tadpoles are not related to other morphological body asymmetries, such as the presence or absence of asymmetrical spiracles, through which the tadpoles expel water that has passed over the gill slits. The absence of any correlates suggests that the lateralization of C-start is dependent strictly on neural asymmetry, and not with external tadpole morphology and possible mechanical bias (Yamashita, Naitoh, and Wassersug, 2000; Oseen,
Newhook, and Wassersug, 2001; Malashichev, 2002; Wassersug and Yamashita, 2002; Malashichev and Wassersug, 2004; Briggs-Gonzalez and Gonzalez, 2016). In amphibian species lacking M-cells Bufo and Bombina (Will, 1986, 1991), no lateralized turning has been observed in the tadpoles. This is, however, not true for Xenopus and Phrynohias (Fig. 2): they have no turning preference despite the presence of M-cells. Whether the system of M-cells is morphologically asymmetric in the latter species is not yet known. If not, than this fact could further support the model suggested by Wassersug and Yamashita (2002).

Another interesting fact is that the lateralization of the rapid turning response disappears by approaching amphibian metamorphosis, when the free limbs take a greater responsibility for control of the body movement. As discussed in the following paragraphs, lateralization also takes place after amphibian metamorphosis, but probably is directed by other neural mechanisms. Turn- 
ing preferences have also been observed in a variety of higher vertebrates, including leftwards turning biases in bobwhite quail chicks Colinus virginianus (Casey and Lickliter, 1998) in the first four days of life after hatching, and rightwards turning preferences in neonatal hamsters (Uziel, Lopesconceicao, Luiz, and Lent, 1996; Uziel, Lopesconceicao, Simpson, and Lent, 1998) and adult humans (Mead and Hampson, 1996). In hamsters, developmental changes in turning preferences during the first 60 days of life, and as adults (where no significant turning preferences were found) was attributed to maturing dopaminergic systems and/or development of the corpus callosum (Uziel, Lopesconceicao, Luiz, and Lent, 1996; Uziel, Lopesconceicao, Simpson, and Lent, 1998). By contrast, the rightwards turning preferences in adult humans were most consistent in males and females who were using oral contraceptives. This was in contrast to regularly cycling females, suggesting the modulation of the motor asymmetry by ovarian hormones (Mead and Hampson, 1996). Obviously, tadpoles could provide a valuable model with which to study the development of lateralized motor preferences and the interaction of specific motor systems (such as the M-cells) and hormones expressed at different stages of development. For example, the M-cells become increasingly thyroid-dependent, and diminish in size to the end of metamorphosis (Hughes, 1976). Interestingly in this context, the lateralization of social response leading to aggregation in Bufo tadpoles, although having a clear visual control, also exhibit some decline when tadpoles approach metamorphosis (Dadda, 2005).

Turning preferences in response to visual stimuli may be of interest when studying the development of lateralized behaviour in tadpoles. Visual lateralization demonstrated in chicks less than two weeks of age is strongly related to hormonal and other maturational factors (Andrew and Dharmaretnam, 1991; Rogers, 1991). Because no visual stimulus was provided in any of the tadpole turning experiments, one could conclude that turning preferences, where present, suggest the existence of purely motor lateralization. However, some caveats exist. Unilateral eye enucleation in Xenopus revealed lower number, length, and diameter of cell processes of the contralateral M-cells following operation suggesting powerful contralateral eye connections (Bezgina et al., 1999). Moreover, C-start response at least in some fish can be modulated by the visual information coming from the contralateral eye (Canfield, 2003).

A number of other experimental protocols were approached to study tadpole lateralized behaviours such as slow turning while exiting a tube, in a T-maze, or escape from approaching barrier (see for review Wassersug and Yamashita 2002). However, these experiments have so far showed left, right, or no turning lateralization to provide no clear cut and easily interpretable results. There was also a discussion in the literature as to whether any phylogenetic trend of tadpole turning lateralization exists. More particularly, the leftwards-turning preferences have been observed in tadpoles of the family Ranidae, Hylidae and Microhylidae and not in the tadpoles of evolutionally earlier families Pipidae or Bombinatoridae. Thus, it is may be possible that lateralized left-directed turning preferences in tadpoles may have occurred in the more recently evolved anuran species of Neobatrachian clade (Goree and Wassersug, 2001; Wassersug and Yamashita, 2002). However, given the small number of species studied over a limited range of developmental stages, and lack of any lateralization in some advances taxa, like Bufo or Phrynohyas, suggest that any final conclusions are premature. Moreover, a recent discovery of right-sided bias in Leptodactylus melanonotus when surfacing to breathe air in the wild (Briggs-Gonzalez and Gonzalez, 2016), may challenge the hypothesis of left-sided tadpole turning bias evolution in Neobatrachia (Goree and Wassersug, 2001). However, right sided biases may also occur when visual information (e.g., on approaching barrier) is analysed by tadpoles (Rogers, 2002). Hence, it is still to be discovered, whether right-sided turning preference in Leptodactylus is indeed an asymmetric C-start, generated by Mauthner cells, and not a slow-motion turning preference.

\section{Lateralized snout-wiping responses}

As one test of motor lateralization in adult anurans, toads and frogs have been scored for forelimb use in removing a mildly irritating object (i.e., plastic balloon, paper strip or piece of plastic-coated wire) from the snout (Table 1). Thus, tactile sensory input and probably also visual input are associated with the task of appropriately guiding the forelimbs. Snout-wiping was an early test developed to assess hand preference in toads of the genus Bufo (Bisazza et al., 1996, 1997) and later applied to a variety of other species with at least three modifications. In the first variant of this test a small elastic plastic balloon was symmetrically placed over the snout of the experimental animal (Bisazza et al., 1996, 1997), in the other two variations a thin moistened strip of paper was positioned across the mouth-nose region either vertically (Bisazza et al., 1997) or horizontally (Malashichev and Nikitina, 2002; Malashichev, 2006a). Figure 3 shows the two types of orientation of the paper strip on the snout (A and B, respectively). Plastic-coated wire placed horizontally and medially over the snout has also been used in tests of forelimb preferences in anurans (Goree and Wassersug, 2001), instead of the moistened paper strip. The results described below from snout-wiping tests of toads of the genera Bufo and Bombina suggest the equivalence of all the testing protocols. However, some important points are worth mentioning when drawing conclusions from all studies of snout-wiping responses. 


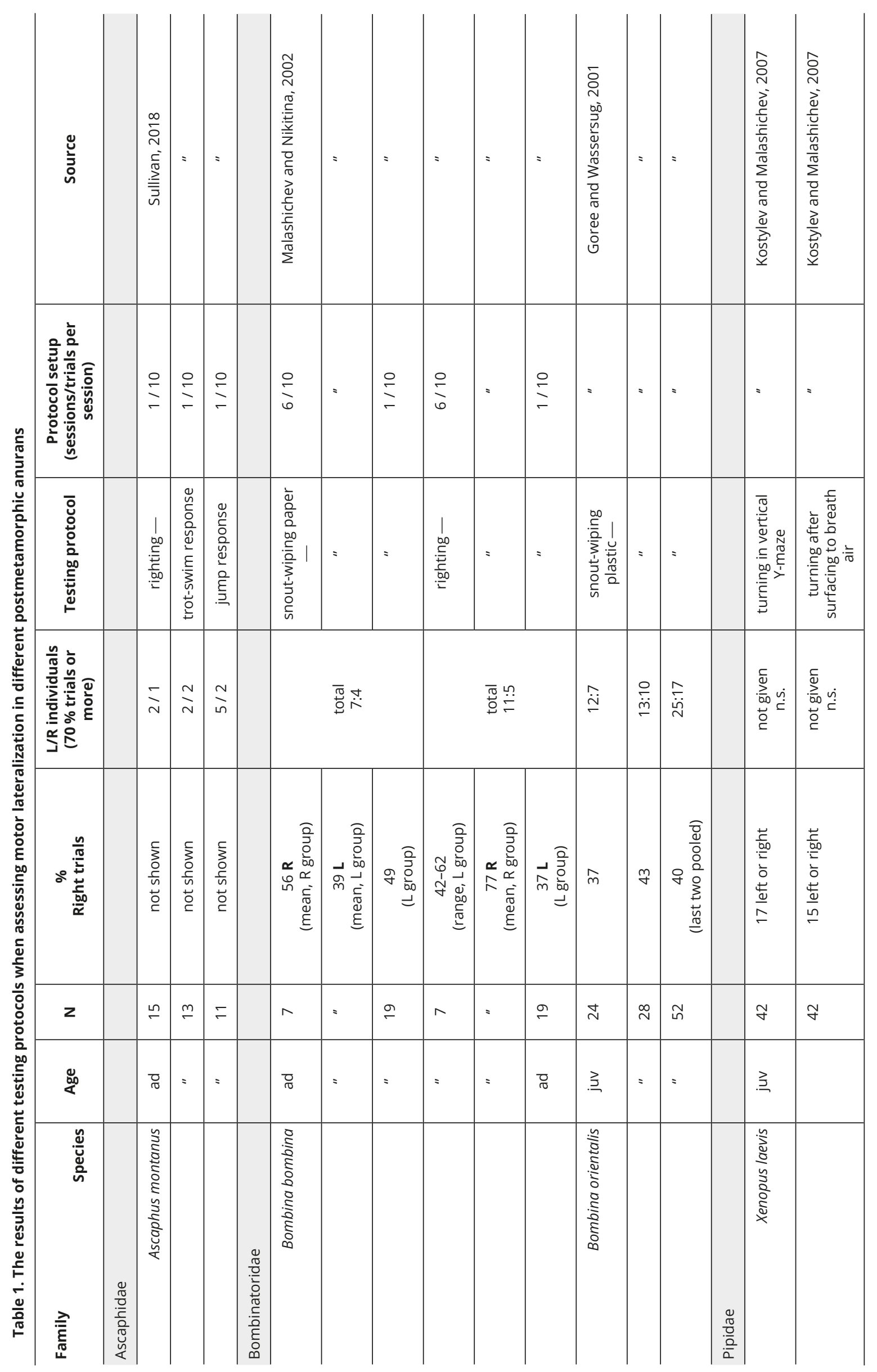




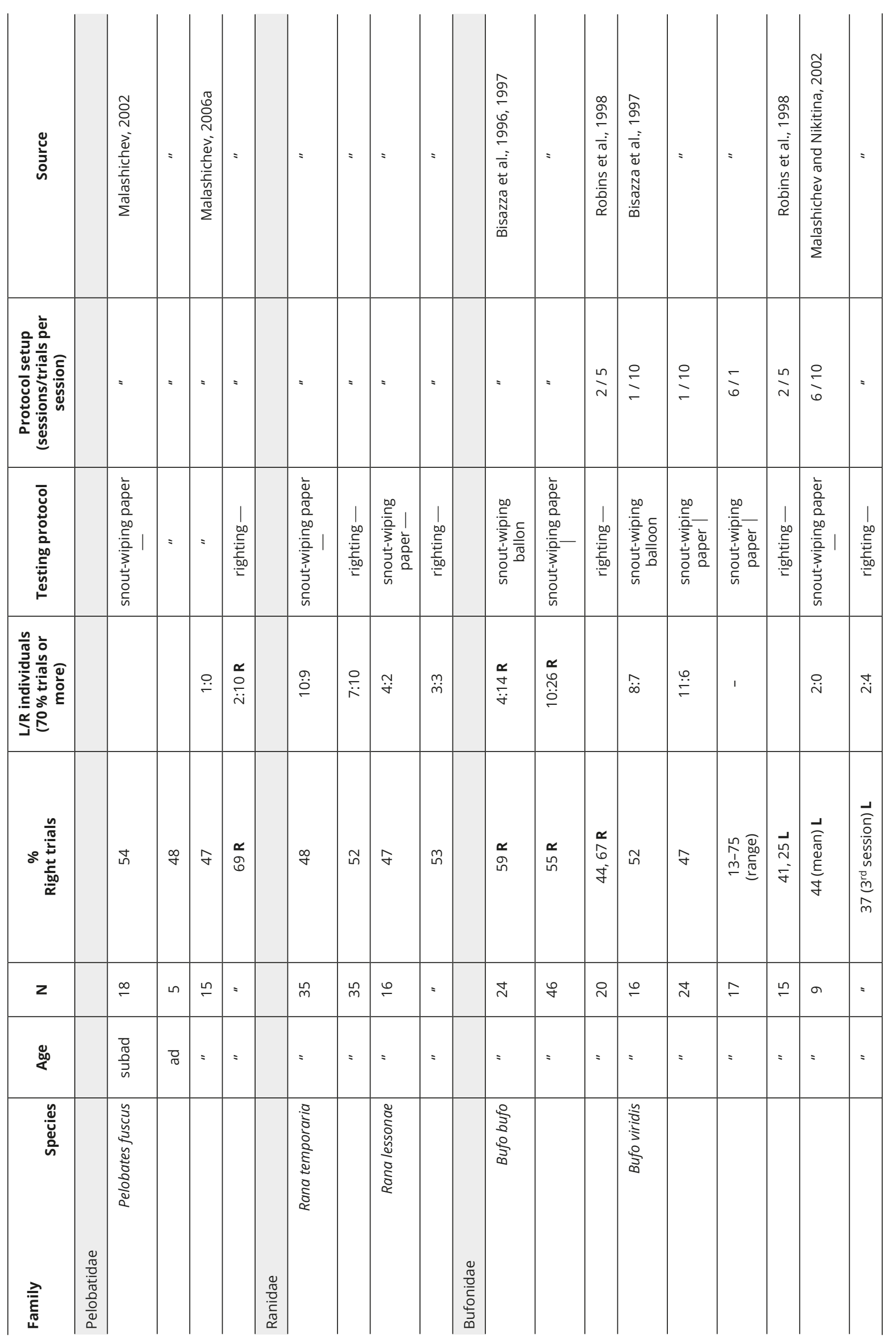




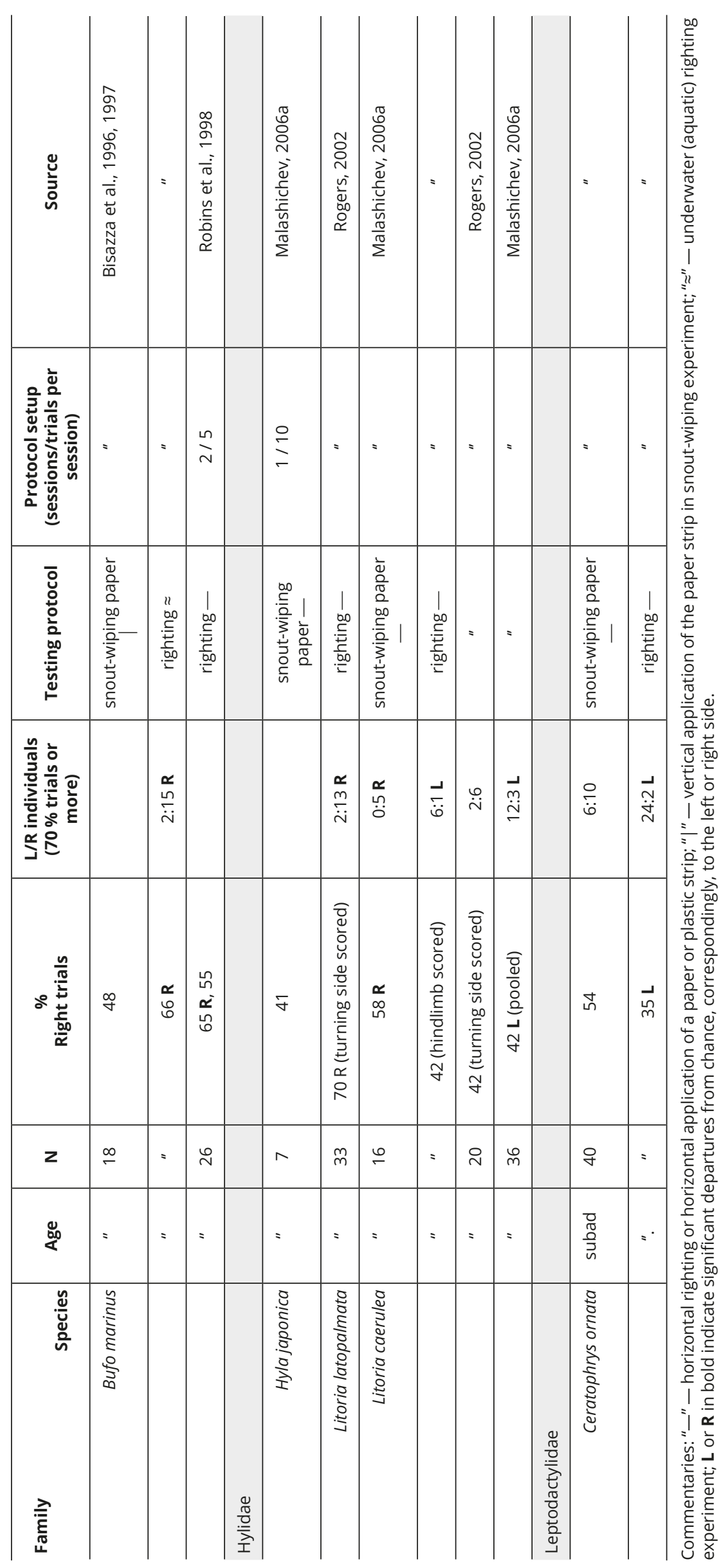



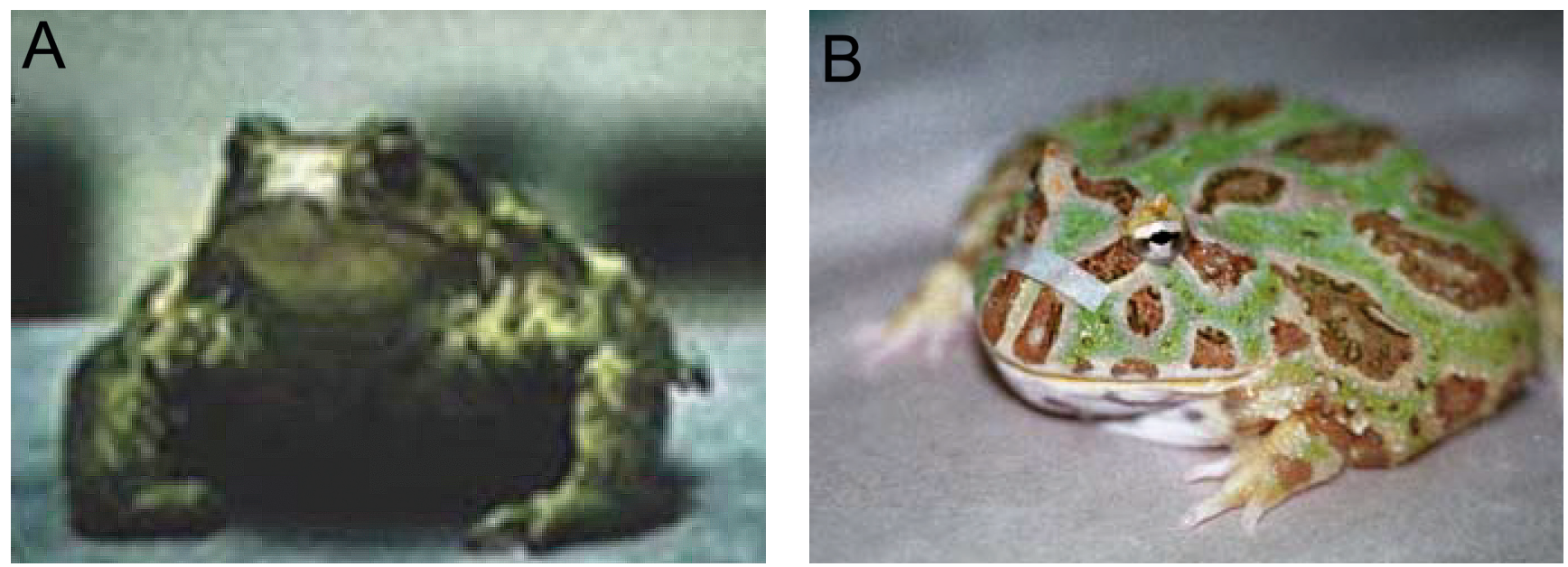

Fig. 3. Snout-wiping experiment. Photos here show the difference in paper strip size and position between two variants of the experimental protocol - "vertical" (A. Bufo bufo; see Bisazza et al. 1996, 1997) and "horizontal" in later reports (B. Ceratophrys ornata; see Malashichev and Nikitina, 2002; Malashichev, 2002, 2006a). Note that the latter variant of paper application guarantees the full covering of the nostrils with the moistened paper strip.
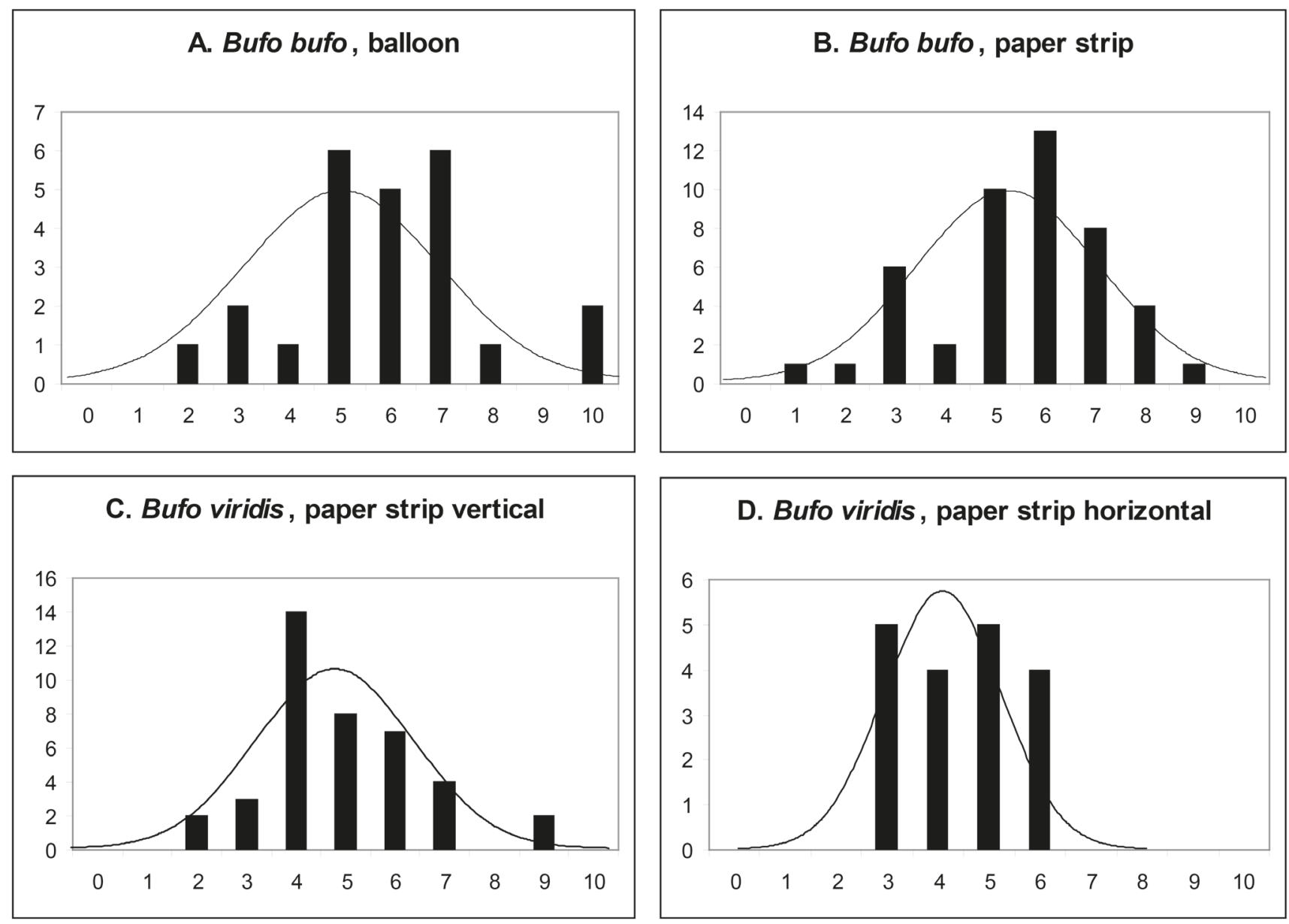

Fig. 4. Results of the snout-wiping experiment obtaining after application of different experimental designs to the same species: a balloon positioned around the head and a vertical version of the paper-strip test applied to Bufo bufo, and two different paper-strip tests applied to Bufo viridis. The number of individuals is plotted against the corresponding number of right-hand trials. Data from Bisazza et al., 1998 (A-C) and Malashichev and Nikitina, 2002 (D). 
In a general sense the snout-wiping test is a relatively straightforward motor task to assess the forelimb preference in adult anurans, requiring directed guidance of the forelimb but with little or no fine-motor control of the hand. The wiping of an obstacle from the vicinity of the snout is a motor element characteristic of prey catching behaviour. That is, the anuran may 'groom' large prey held partially with the mouth, removing debris and assisting to orient the prey so that it may be swallowed more easily. The 'prey-grooming' behaviour may follow both successful and unsuccessful tongue strikes and bites at prey. We currently do not know which of the test modifications may stimulate neural inputs involved in part to the feeding responses, or other neural circuits (e.g., asymmetry in the facial nerve). What has been suggested is that the original procedure, using the plastic balloon as the object of irritation, may be stressful for animals (Bisazza et al., 1997), possibly because it also occludes full vision. Importantly, some B. bufo toads regularly used hindlimbs in attempts to remove the balloon from the head (Bisazza et al., 1997), a behaviour rarely observed when removing a strip of moistened paper from the snout and one suggestive of a high level of agitation in toads tested in this manner. On the other hand, when a visually-inconspicuous strip of paper is positioned horizontally across the nostrils (Fig. 3B), it reduces normal lung ventilation and could elevate autonomic arousal. Conceivably, the snout-wiping test also can be arduous task for the animal forced to support the body weight with only one forelimb, whilst wiping the obstacle from the snout with the contralateral forelimb (Malashichev, 2002). Thus, asymmetric structure of the pectoral girdle in arciferal anurans as will be fully explained below may influence the results of the snout-wiping test, at least in some species (Malashichev and Nikitina, 2002).

\section{SNOUT-WIPING RESPONSES IN}

B. BUFO, B. VIRIDIS AND B. MARINUS

Only one species so tested of the genus Bufo has shown strong and persistent forelimb preference in the snout-wiping tests. B. bufo showed a right forelimb preference to remove either a small plastic balloon or a moistened paper strip positioned vertically across the snout of the toad (Fig. 4A, B; 59\% and 55\% right-forelimb preference, respectively: Bisazza et al. 1996, 1997). In contrast, B. marinus and B. viridis were initially not found to have significant forelimb preferences to remove the paper strip positioned horizontally (B.marinus) or vertically (B. viridis; Fig. 4C) from the snout $(48 \%$ and $47.5 \%$ right-forelimb preference, respectively: Bisazza et al. 1997). The latter species revealed higher sensitivity to the procedure (i.e., was frequently observed engaged in tonic immobility) and was retested less intensively, when each animal was presented a single trial a day dur- ing six consecutive days, minimizing the stressor of handling. A significant difference between the first and the second half of the trial set was noted in male B.viridis, with a preference to use the left forelimb to remove the vertical strip (Bisazza et al. 1997; see also Table 1). In a similar snout-wiping test to remove a horizontal strip by male and female B. viridis, a left forelimb preference were found with significant group lateralization on only two of six days of repeated more intensive testing (Fig. 4D; 10 trials per day; Malashichev and Nikitina, 2002). The leftward bias, although not reaching significance on each day of testing, was consistently observed in the group of toads ranging from 39 to $48 \%$ right-forelimb preference. Much later, this toads were found to preferentially use the left forelimb in naturally occurring behaviour, e.g., when feeding and, hence, wiping in order to help themselves to ingest the food - a mealworm placed in front of the toad (Sovrano, 2007). Taken together these data revealed right forelimb preference in B.bufo and left forelimb preference in $B$. viridis for the snout-wiping task.

An important outcome from this brief comparison of testing protocols is that both B.bufo and B.viridis showed persistence in forelimb preferences whatever modification to the snout-wiping test used, either significant or not (compare Figs. $4 \mathrm{~A}$ and B, and Fig. $4 \mathrm{C}$ and D). Unfortunately, a group of B. marinus was tested only once under a relatively less intensive three trials per day / six days condition (see summary Table 1) and it is not known whether this species would show any forelimb preference were the test to be slightly modified. The snout-wiping data collected would be even more interesting as this species was found to be strongly lateralized in its forelimb preference revealed in other behavioural tests, e.g., 'aquatic righting', also previously termed the "inversion-submersion" test (Bisazza et al., 1996, 1997; Robins and Rogers, 2002). This further suggests that the lack of limb lateralization revealed in a single particular test is not the indicator of an absence of limb lateralization in general. Nevertheless, the snout-wiping test, although not as sensitive as tests of righting responses for revealing limb preferences (see below), may be successfully used to estimate the relative lateralization in a variety of anuran species.

\section{A COMPARATIVE SURVEY OF SNOUT-WIPING RESPONSES IN ANURANS}

Few other species studied so far outside the Bufo genus showed significant forelimb lateralization in the snout-wiping test. Bombina toads of the family Bombinatoridae have been found to have no significant forelimb preference in snout-wiping experiments (Goree and Wassersug, 2001; Malashichev and Nikitina, 2002). Young postmetamorphic Bombina orientalis did not possess forelimb preferences in removing a piece 
Table 2. Snout-wiping responses in anurans provided 10 successive trials

\begin{tabular}{|c|c|c|c|c|c|c|c|}
\hline & \multirow{2}{*}{ Population } & \multirow[b]{2}{*}{$\mathbf{N}$} & \multicolumn{2}{|c|}{$\begin{array}{l}\text { No. of animals with strong } \\
\text { forelimb preference }(\geq 70 \%)\end{array}$} & \multirow{2}{*}{ G } & \multirow{2}{*}{$\mathbf{p}$} & \multirow{2}{*}{$\begin{array}{l}\text { Mean \% Right } \\
\text { (SEM) }\end{array}$} \\
\hline & & & Left & Right & & & \\
\hline \multirow[t]{3}{*}{ P. fuscus } & Udmurtia, Russia ${ }^{2}$ & 18 & 1 & 4 & 0.96 & NS & $53.89(3.1)$ \\
\hline & Tambov, Russia ${ }^{1}$ & 15 & 1 & 0 & -1.38 & NS & $46.67(2.5)$ \\
\hline & Total & 33 & 2 & 4 & 0.64 & NS & $49.7(2.2)$ \\
\hline R. temporaria & St. Petersburg, Russia ${ }^{1}$ & 35 & 10 & 9 & 0.05 & NS & $48.29(3.8)$ \\
\hline R. lessonae & Pskov, Russia ${ }^{1}$ & 16 & 4 & 2 & 0.64 & NS & $47.5(3.8)$ \\
\hline C. ornata & captive breeding $^{1}$ & 40 & 6 & 10 & 1.01 & NS & $54.75(2.5)$ \\
\hline L. caerulea & captive breeding ${ }^{1}$ & 16 & 0 & 5 & 6.93 & $<0.01$ & $58.1(2.8)$ \\
\hline
\end{tabular}

1. Data from Malashichev, 2006a.

2. Data from Malashichev, 2002.

of plastic-coated wire oriented horizontally across the snout (37-43\% right forelimb trials with $P$ value varying from 0.1 to 0.7 in three groups of toadlets; Goree and Wassersug, 2001); this was the case even in individuals that were found to possess left or right turning preferences when tadpoles. Similarly, adult Bombina bombina were not found to have forelimb preferences to remove a horizontal strip of paper from the snout in trials conducted over six days of testing (i.e., in 60 trials, provided in conditions similar for those applied to B.viridis; Malashichev and Nikitina, 2002). Individual B. bombina toads demonstrated labile preferences in subsequent days and could also use the forelimbs simultaneously in a bimanual movement when removing the paper from their snouts: the bimanual wiping was observed in $22 \%$ of trials in experimental groups and up to $60 \%$ in individual toads. (These trials were discarded from the analysis and the trials were immediately replaced.)

The snout-wiping test was subsequently applied to representatives of the families Pelobatidae, Ranidae, Hylidae, and Leptodactylidae (Malashichev, 2006a). The dimensions of the horizontally positioned paper strip were modified according to the relative snout-vent length of each species. Individual animals were tested in similar conditions with uniform lighting provided to eliminate this potentially confounding effect. Ten successive trials to remove a paper strip from the snout were provided to each individual and the forelimb used in wiping the strip was scored. Table 2 summarizes the number of right and left trials in all the species studied using this protocol.

The snout-wiping test in European spade-foot toad Pelobates fuscus (Pelobatidae) revealed no dominance in forelimb use at population level in this species (Table 2; Fig. 5A and B). Moreover, only one animal in the sample showed a somewhat strong preference in its (right) forelimb use. This result is in well correspondence to previ- ous findings in other populations (Malashichev, 2002), all belonging to the same "Eastern" type of P.fuscus (Borkin, Litvinchuk, Rosanov, and Milto, 2001). Similarly, in both species of true frogs (Ranidae) examined, the more terrestrial Grass frog, R. temporaria (Fig. 6), and the more aquatic Pond frog, R. lessonae, revealed no limb dominance at population level in the snout-wiping test (Table 2; Figs. 5C and D). Some individuals showed preferential right or left forelimb use, while the majority were ambidextrous. These results suggest that true frogs, like spade foot toads, are also ambipreferent in snout-wiping response (Table 2).

A representative of Leptodactylidae s.l., the Ornate horned frog Ceratophrys ornata were not strongly lateralized either (Table 2, Fig. 5E) although the percentage of the right forelimb use (55\%) approached significance (Student's $t$-test: $t=1.915 ; p=0.06)$. Of note was that the horned frogs used the forelimbs with a greater range of limb movements compared with species otherwise non-lateralized for limb use when snout-wiping (e.g., true frogs). C.ornata were repeatedly observed performing with either forelimb, often alternately, as many times as required to remove the paper completely from the head and not only from the snout (Fig. 7). In the majority of cases other species (except Bufo) preferred only to expose the nostrils with a single quick movement of one of the forelimbs, rarely attempting to remove the paper completely if it remained partially adhered to the head skin. Contrasting are the data on forelimb preferences for snout-wiping in a hylid frog. Australian Green tree frogs, Litoria caerulea, showed highly significant lateralization for use of the forelimbs (Table 2; Fig. 5F), with the bias towards preferential use of the right forelimb at the population level.

A number of hypotheses have been developed to explain the causes of lateralization in the forelimbs of toads and frogs when wiping an obstacle from the snout, and we consider them in order of chronology. 

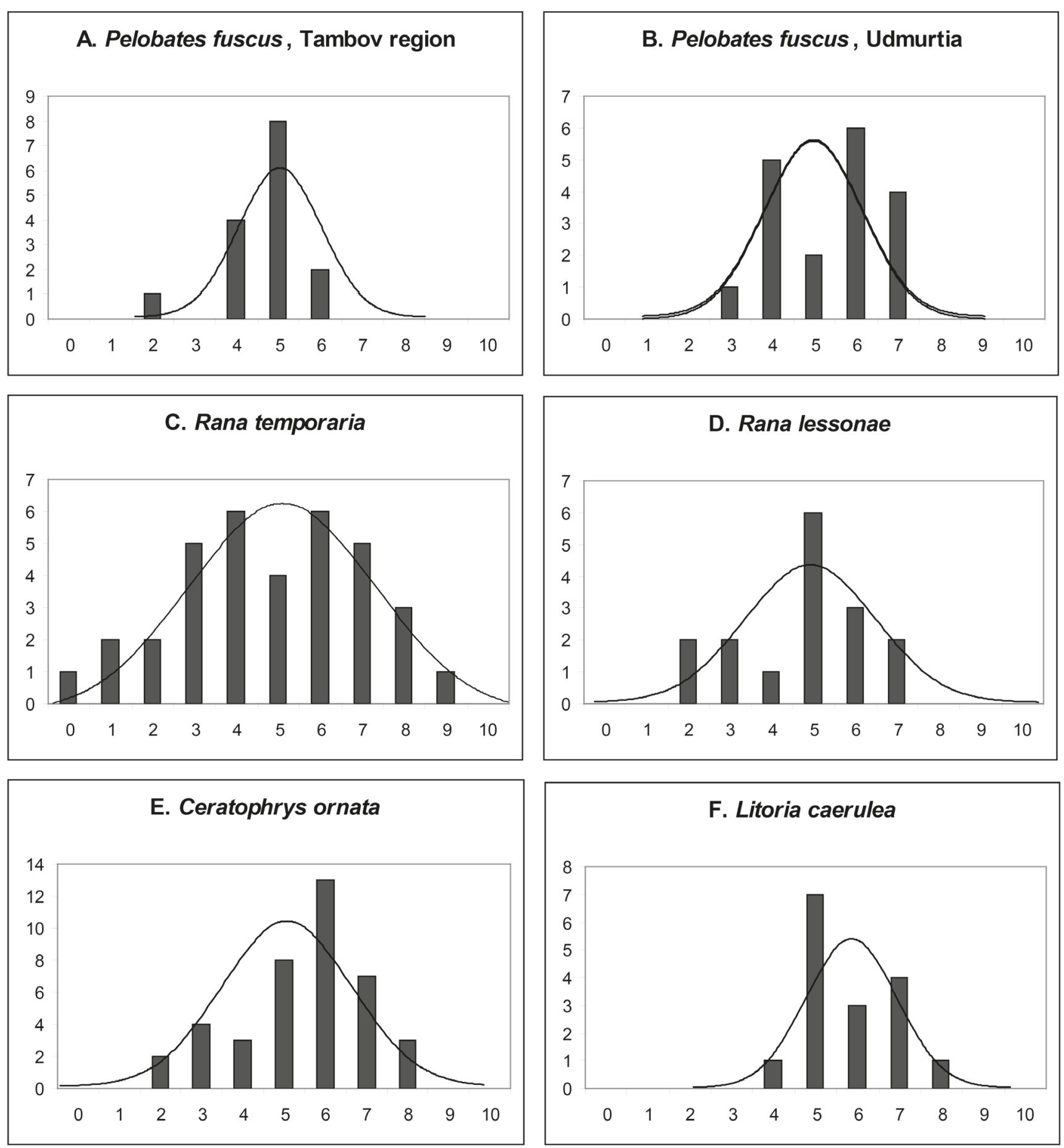

Fig. 5. Results of the "horizontal" paper-strip snout-wiping test in anurans. See Fig. 4 for other details. Data from Malashichev, 2002 (A) and Malashichev, 2006b (B-F).

\section{A. Food orienting, grooming, grasping, and emesis behaviours}

Many non-mammalian species, e.g., birds, use tools or manipulate objects with limbs, e.g., parrots (Harris, 1989; Giljov, Karenina, and Malashichev, 2011), or with the medially positioned bill, e.g., New Caledonia crows (Rutledge and Hunt, 2004), the actions being strongly lateralized in terms of footedness and side of the bill used. Tool use and tool construction, although invariably associated with lateralized limb preferences in higher vertebrates, have not been reported in amphibians. Limb preferences without tool use have also been assessed in many mammalian and avian species, commonly with tasks requiring the acquisition or holding of food objects (e.g., chimpanzees (McGrew and 

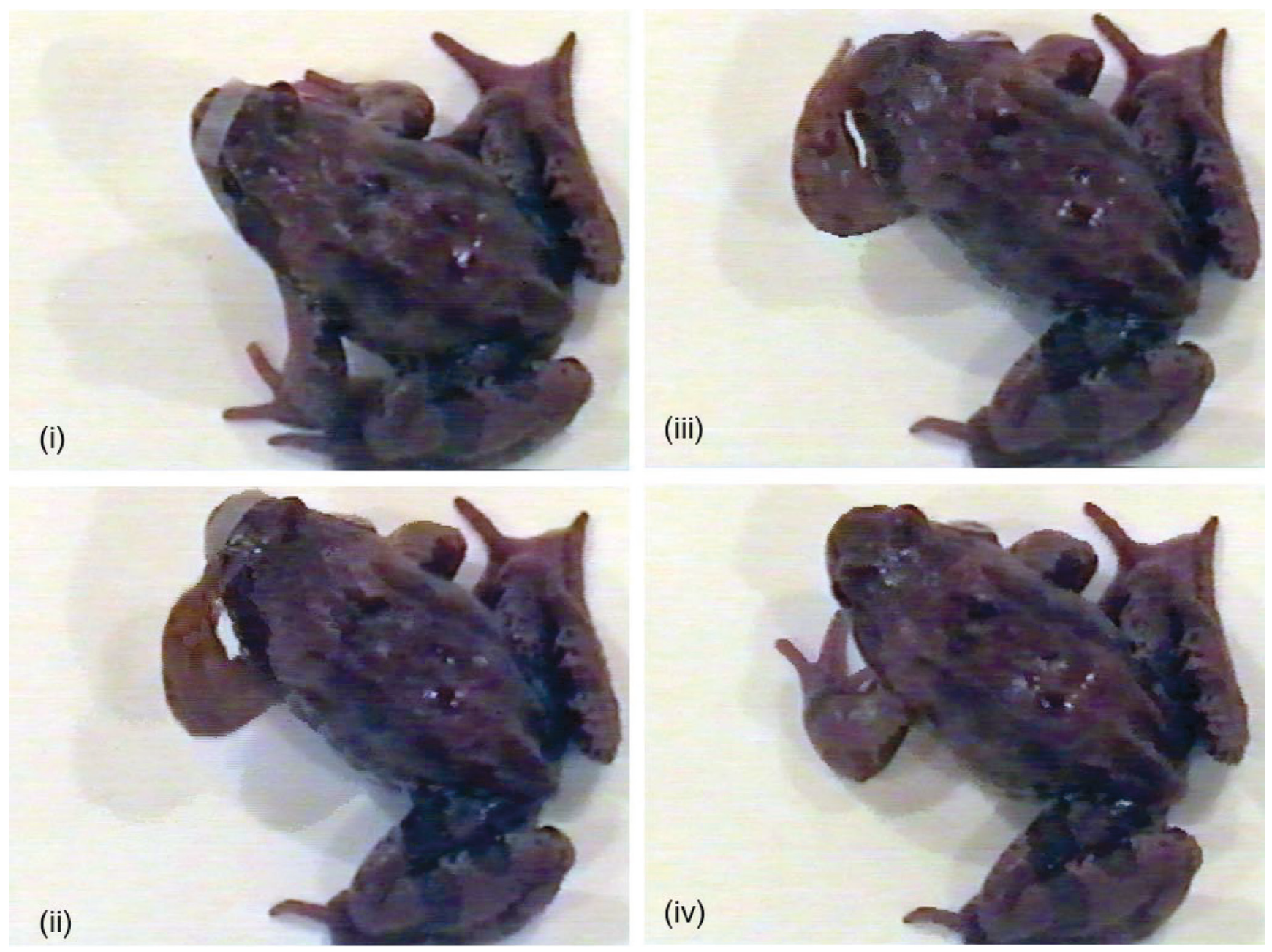

(iv)

Fig. 6. A video-sequence of one trial during paper-strip snout-wiping test in Rana temporaria. Left forelimb is used to wipe our the wet paper from the snout.

Marchant, 1992); sifakas (Mason, Wolfe, and Johnson, 1995); prosimians (Ward, Milliken, and Stafford, 1993); rats (Brácha, Zhuravin, and Bures, 1990); kangaroos and wallabies (Giljov, Karenina, Ingram, and Malashichev, 2015); parrot species (Rogers and Workman, 1993); chicks (Tommasi and Vallortigara, 1998)). However, unlike many higher taxa that can use their limbs for catching and manipulating prey, the grasping movements in anurans that would enable their limb preferences to be directly compared with avian and mammalian species are rare (Gray, O'Reilly, and Nishikawa, 1997). The medially positioned tongue and jaws are used by anurans to attack and acquire potential prey, with the forelimbs used secondarily to orient the prey in front of their snout and assisting swallowing. Nevertheless, original reports of right-handedness in toads discussed grooming (snout-cleaning) behaviour and the use of forelimbs in feeding (food orientation) as possible correlates of motor lateralization of forelimbs in toads (Bisazza et al., 1996, 1997). The following reviews definitions of five different types of forelimb use in prey manipulation in anurans (Gray, O'Reilly, and Nishikawa, 1997), behaviour generally similar in both the goal and motor acts used in higher vertebrates when feeding. One or both forelimbs could be involved with each of the five movement patterns described from video sequences:

(1) 'Scooping' is the pattern whereby the forelimbs extend anteriorly with the fingers splayed, and the back of the hand is used to shove the prey item posteriorly into the mouth (Gray, O'Reilly, and Nishikawa, 1997). This motor action is a primitive behaviour pattern occurring in high frequencies in aquatic species, especially in Hymenochirus and Xenopus. Although principally this behaviour could be considered as a basal characteristic, and thus potentially a key for the development of forelimb lateralization in anurans, in practice it typically involves simultaneous or alternative operation of both forelimbs (Gray, O’Reilly, and Nishikawa, 1997). However, litthe is known of feeding sequences involving scooping and, moreover, it's possible lateralization even in aquatic species common to laboratories, such as 

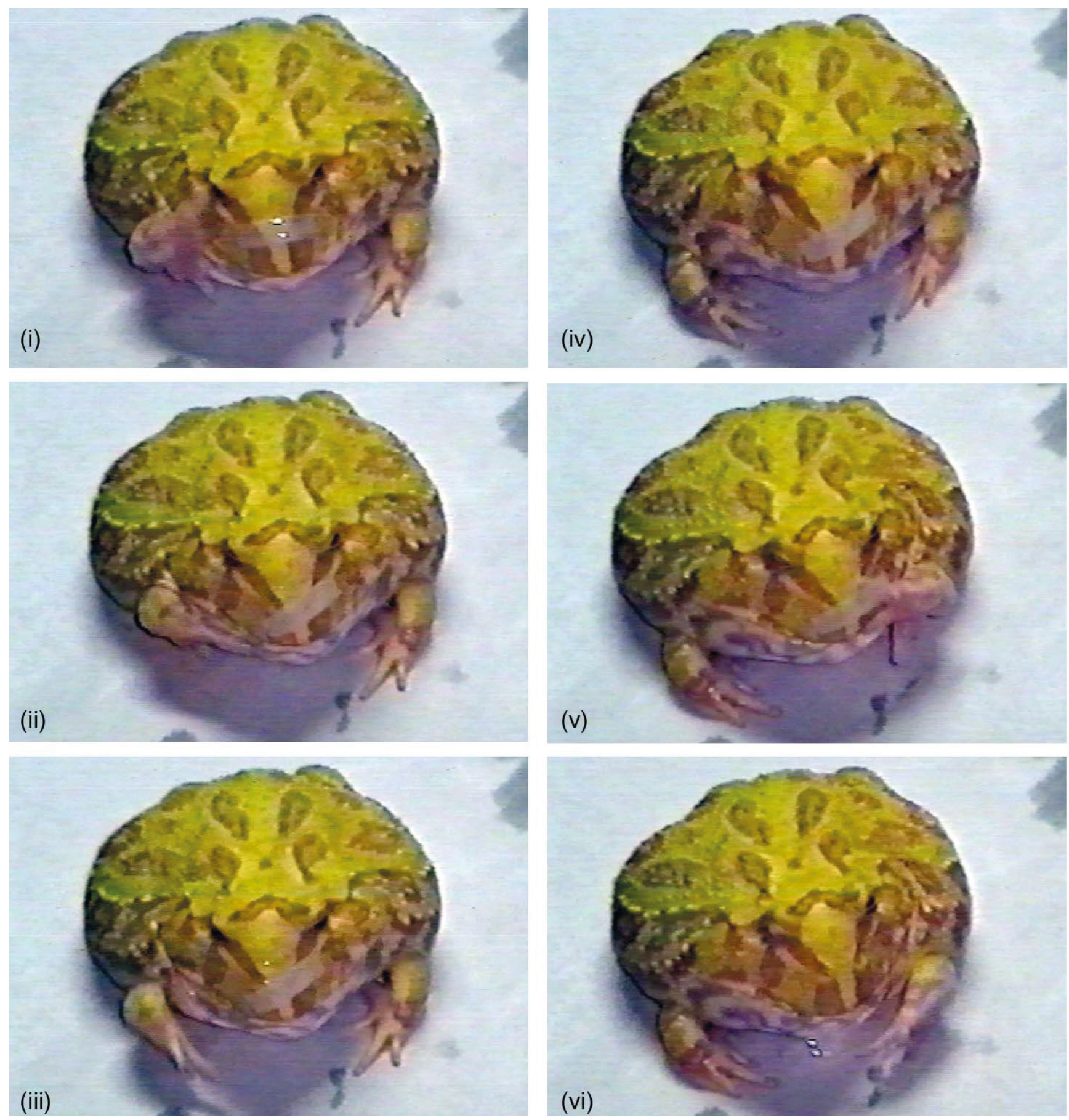

Fig. 7. A video-sequence of one trial during paper-strip snout-wiping test in horned frog Ceratophrys ornata. This individual demonstrate "accuracy" while fulfilling the test. After unsuccessful attempt to remove the paper from the snout with the right forelimb, the frog completes the action with additional movement with the left forelimb to remove the asymmetrically positioned paper strip. As the first attempt was addressed when the paper was adhered symmetrically, the overall trial should be scored as right-handed. This alternate limb-use behaviour is very common for Ceratophrys.

X. laevis. Thus, a high-speed video sequencing and analysis of scooping behaviour in anurans warrants attention in the future.

(2) 'Wiping' is defined as feeding behaviour in which the palm of the forelimb is used to push prey, protruding laterally from the mouth, forward toward the midline (Gray, O’Reilly, and Nishikawa, 1997). Wiping while feeding is also a primitive movement pattern and was observed in most of the species examined, and similar to the prey-grooming behaviour described earlier, as well as snout-wiping behaviour. In many cases it is performed with only one of the forelimbs. It might be expected that such a motor pattern is well-developed in burrowing anurans, which must invariably 
deal with prey-grooming and snout-wiping during the course of feeding and other daily activities. These traits together, possibly, may be associated with lateralized forelimb use in those species. However, lateralization here may simply reflect the opportunity to measure it through the existence of the appropriate reflexes. For example, wiping sequences were rarely observed in aquatic Xenopus and Hymenochirus. Snout-wiping tests in species of these genera have not yet been conducted.

Interestingly, bufonid toads appear to be losing well-defined wiping (as well as scooping) behaviours associated with feeding. Bufo marinus is one species among others not observed utilizing wiping behaviour at all in normal life (Gray, O'Reilly, and Nishikawa, 1997); a species also lacking lateralization in the snout-wiping test (Bisazza et al., 1997). On the other hand, the strong lateralization in forelimbs is, nevertheless, shown in other members of the same genus and even in B. marinus in other experiments ('aquatic righting responses': see below).

Whether natural wiping and grooming reflexes play a role in lateralization in forelimb movements is still uncertain. Ceratophrys, an 'ambush' species, was noted to use forelimbs in wiping actions actively, even more intensively and directing than other species of frogs, but nevertheless the tendency to use right forelimb in the snout-wiping test did not reach, although approached, significance (Malashichev, 2006a).

(3) 'Prey stretching' behaviour is performed by grasping or pinning one end of the prey such as a mealworm or waxworm to the substrate, while the mouth grips the other end of the prey, pulling the head away from the anchoring forelimb. Prey stretching is a distinct behaviour, found in six unrelated species to date (Gray, O'Reilly, and Nishikawa, 1997). Although sometimes it might be asymmetrical (when only one forelimb is in use or when limbs are alternated) it is considered unlikely as an important correlate with other forms of forelimb lateralization. One of the genera elaborating such a pattern of feeding - Bombina - was not to be shown lateralized in snout-wiping experiments (Goree and Wassersug, 2001; Malashichev and Nikitina, 2002). However, the plausibly different roles for one forelimb to hold the prey item distantly, and the other to stretch the prey with the mouth-to-end movements should not to be overlooked in future studies of other species. It would be also interesting to see whether the individual asymmetry in prey stretching in Bombina is associated with the skeletal asymmetry in the shoulder apparatus.

(4) 'Grasping', when the fingers wrap around the prey while it is transported to the mouth, or
(5) 'grasping with wrist rotation', when the movement is similar to simple grasping, but the wrists rotate so that the palm are oriented towards the mouth, are observed only in arboreal families, the latter one - only in Hylidae (Gray, O'Reilly, and Nishikawa, 1997). These movement patterns seem to be a strong adaptation to climbing and thus can be considered as a unique and derived character. Both kinds of grasping movements were used to capture prey and in each of the consequences observed, the frog was recovering from missing or dropping the prey, also the normal lunge and tongue movements were absent. There is yet no clear report on whether tree frogs can grasp the prey unilaterally. Should it be so, then prey capture in arboreal anurans could be compared to visually-guided food reaching in insect-feeding prosimians e.g., small-eared bush-babies (Rogers, Ward, and Stanford, 1994), lories (Nekaris and Tab Rasmussen, 2003), which hold the tree branch with one hand, whilst catching prey with the other hand. Such a motor specialization of forelimbs in amphibians could possibly correspond with lateralization of limb preferences. However, all the observations on grasping in anurans were made in laboratory and we have no field data on this behaviour in natural populations.

The other kind of "grasping" (or more appropriately, 'clasping') was discussed in early report on motor lateralization in toads that is grasping of females in amplexus made by males during breeding season (Bisazza et al., 1997). It is also unlikely that using forelimbs in clasping the females, and in male-male fights when competing for females, are strong correlates with limb lateralization. Apart from the symmetric character of these behaviours it should be noted that the greater tendency to be lateralized was found in females rather than in males at least in B.bufo (Bisazza et al., 1997). However, this discussion revisits the interesting issue of seasonal variation in the hormonal levels of both sexes and thus the possible fluctuations in the relative level of behavioural lateralization in general.

Naitoh and Wassersug (1996) suggested an alternative explanation for right handedness in toads. They drew attention to the fact that anurans have strong emetic reflexes provoked by a toxic material entering the toad's stomach. The reflexes enable not only the contents of the stomach to be regurgitated, but also the forcible prolapsing of the stomach. Given the stomach in normal animals is positioned on the left side of the body the prolapsed stomach consequently hangs to the right. Frogs and toads remove the remaining vomitus from the surface of the prolapsed stomach with the right forelimb as it lies out of the reach of the left forelimb. That emet- 
ic behaviour has some relationship with the establishment of handedness in toads is an intriguing hypothesis (Naitoh and Wassersug, 1996), but implies that once the stomach normally is situated on the left in all the vertebrates, including anurans, the latter should necessarily be right-handers (at least in species with a stomach which can prolapse). However, most species tested with the snout-wiping experiment have been found to be ambipreferent with a weak, non-lateralized tendency towards the left and not right forelimb (Malashichev and Nikitina, 2002; Malashichev, 2006a). In addition, the 'emesis' hypothesis predicts little about the possible lateralization in the hindlimbs, as derived in other contexts, nothing to say about possible role of perceptual cues and the overall specialization of the right and the left sides of the central neural system.

The short account of Naitoh and Wassersug (1996) took into consideration, however, a possible link of the lateralized motor pattern to the visceral asymmetric morphology or function. This possibility was reviewed later in more detail (Malashichev, 2002; Malashichev and Wassersug, 2004; Malashichev, 2006b). It appears that there is little evidence, if any, linking the visceral and neurobehavioural asymmetries in frogs, and, more broadly, even in other vertebrate classes. For instance, there were no correlation found between the lateralization in the forelimb use in the snout-wiping test and the asymmetry in spiracle (also gut opening) position (Malashichev, 2002). So far, few original studies have addressed this issue in full depth in anuran amphibians, however, a survey of the existing literature provide little support for a clear developmental link between the behavioural lateralizations and visceral organ asymmetry in any of the vertebrate species studied (Malashichev and Wassersug, 2004; Briggs-Gonzalez and Gonzalez, 2016).

\section{B. Skeletal morphology}

The long bone weight and length are occasionally considered as a possible correlate to handedness of limb use (Malashichev, 2002; Robins and Rogers, 2002). However, the study of both behavioural handedness and skeletal asymmetry are rare in higher vertebrates and usually not found in anurans. Even in the latter cases the correlations might be explained in a number of different ways, which are not considered here in greater detail. However, there is another type of skeletal asymmetry which may be important for interpretation of snout-wiping responses, namely, the asymmetry in the shoulder girdle. Two principal types of the shoulder girdle structure occur in both anuran and caudate amphibians: arciferal and fermisternal girdles. Arciferal girdles are characterised by thin bilateral epicoracoid plates with one plate arcing to overlap the other (Fig. 8A). Fermisternal gir- dles are characterised by thick bilateral cartilaginous epicoracoid plates that are meeting to fuse at the midline beneath the body (Fig. 8B). In the former case two possible states of the shoulder girdle structure occur: either with the right epicoracoid overlapping the left to take the upper (dorsal) position (Fig. 8C) or in the reverse configuration (Fig. 8D).

Some authors (Borkhvardt and Ivashintsova, 1995) suggested a link between the shoulder girdle structure and lateralized behaviour. A correspondence between the type of the epicoracoid overlap (right-over-left or left-over-right) and, correspondingly, the right-sided or left-sided direction of lateralization of the snout-wiping response was indeed found in one species of fire-bellied toads, B.bombina (Malashichev and Nikitina, 2002). Two groups of animals, those with the right-over-left and the left-over-right configurations of the pectoral girdle arcifery, demonstrated opposite directions of forelimb lateralization to the right $(56.17 \pm 2.47 \%$ right-handed trials) and the left $(35.00 \pm 6.71 \%$ right-handed trials), respectively (see also Table 1). The difference was significant between the two experimental groups, showing the appropriate tendency through the whole testing period of six days. However, another study of B. marinus righting behaviour revealed no link between the structure of the shoulder apparatus and forelimb preference (Robins and Rogers, 2002). The latter authors used a different experimental approach, namely, the 'aquatic righting' experiment (see below) applied to a species of much different ecological type and behaviour. Hence, the most plausible explanation of the differences obtained in two consequent studies between the two unrelated species of toads is based on the difference in habitats and tests applied (Malashichev, 2002).

Indeed, the fire-bellied toads are semi-aquatic anurans, spending much of their lifetime in water rather than on land, rarely facing the need to lift the body above the substrate with the help of their forelimbs. Their jumps are low and their strong hindlimbs are used in swimming, rather than jumping. Therefore, the forelimbs may be less strong as they also play a lesser role in jump amortization when landing. Moreover, the fire-bellied toads usually rest on the belly, when on land (Malashichev, personal observation). The snout-wiping test suggests the support of the body is made only with one forelimb, while the contralateral forelimb is lifted wiping the paper-strip from the snout. The application of this test to such a "weak-chested" species as B.bombi$n a$ may, therefore, be an arduous task; hence even a slight asymmetry in the shoulder girdle could be the source of potential behavioural bias. On the other hand, B. marinus is a strong handed species, easily lifting its body far above the substrate (e.g., crouched pose when looking at prey) and landing on forelimbs when jumping. The aquatic-righting experiment (see below) provides a test 


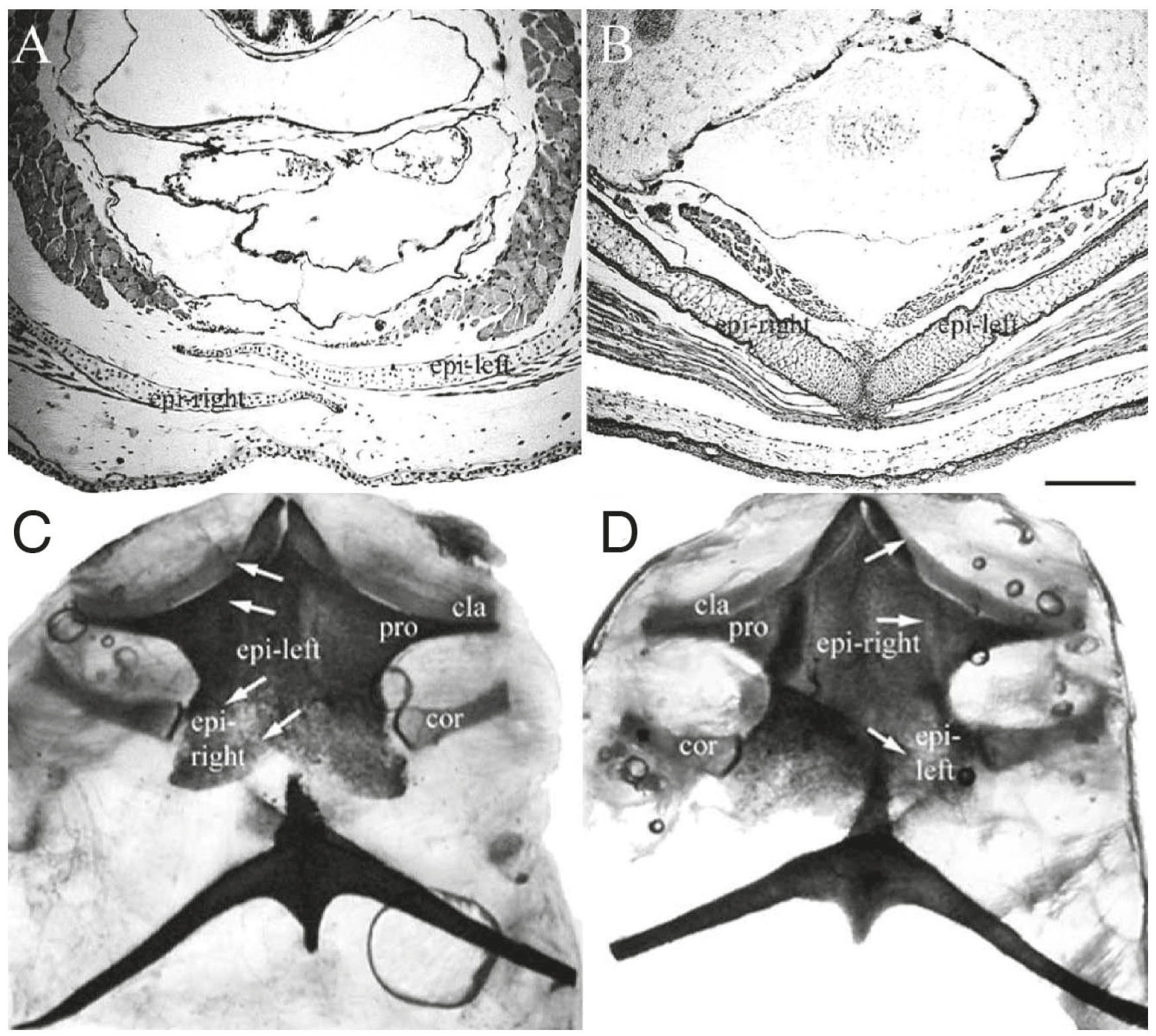

Fig. 8. Transverse histological sections through the thoracic part of the body of the metamorphosing Triturus vulgaris (A) and Rana temporaria (B). Note the epicoracoid overlap, forming "left-on-top" configuration of the shoulder girdle in the arciferal species (A) and only a slight asymmetry in the joining of contralateral epicoracoids in the fermisternal species (B) [epi-left = left epicoracoid; epi-right = right epicoracoid] . Scale bar is $185 \mathrm{~mm}$. Ventral view of alizarin red and alcian blue whole mount preparations of the shoulder girdles of Bombina bombina. (C) R. top phenotype, where the right epicoracoid is in dorsal, deeper position, while the left epicoracoid is superficial and clearly visible. (D) "left-on-top" phenotype, where the left epicoracoid is in dorsal, deeper position, the right one is superficial [cla = clavicle, pro = procoracoid, cor $=$ coracoid, epi-left = left epicoracoid, epi-right = right epicoracoid, arrows show the visible margin of the most superficial epicoracoid]. Reprinted from Malashichev and Nikitina (2002; Laterality, Vol. 7, Issue 1, p. 3, Fig. 1 with minor change) by permission of Psychology Press Ltd., Hove, UK.

of forelimb preferences in conditions not otherwise physically taxing for the toads, potentially masking the influence of the skeletal asymmetry on lateralization of the motor responses; hence the correlation between the type of the epicoracoid overlap and the lateralized use of the forelimbs was not found in this species (Robins and Rogers, 2002). In other aquatic species, like Xenopus laevis, we also found low and not significant correlation between the skeletal asymmetry in the epicoracoids and the lengths of long bones of postmetamorphic frogs on the one hand, and lateralization of turning in
Y-maze and when surfacing to breath air on the other hand, although there were strong and significant correlation between two skeletal asymmetries (Kostylev and Malashichev, 2007). Altogether, these data suggest that skeletal asymmetries and behavioural lateralization in motor responses with forelimbs are different phenomena in anurans.

Although the epicoracoid asymmetry should be taken into account when conducting or interpreting the results from the snout-wiping test, a cross-species com- 
Table 3. Skeletal morphology and limb lateralization in anurans

\begin{tabular}{|c|c|c|c|c|}
\hline & Shoulder girdle structure & $\begin{array}{l}\text { Forelimb preference } \\
\text { (Snout-wiping) }\end{array}$ & $\begin{array}{l}\text { Pelvis articulation } \\
\text { type } 1\end{array}$ & $\begin{array}{c}\begin{array}{c}\text { Hindlimb } \\
\text { preference }\end{array} \\
\text { (Horizontal } \\
\text { righting) }\end{array}$ \\
\hline Bombina & $\begin{array}{l}\text { Partial or full epicoracoid overlap; } \\
\qquad 2: 1-3: 1 \text { Lvp }\end{array}$ & NO & Type I & NO \\
\hline Pelobates & Full epicoracoid overlap; 10:1 Lvp & NO & Type I & YES \\
\hline Rana & $\begin{array}{l}\text { Fermisternal epicoracoid connection; } \\
\text { no overlap }\end{array}$ & NO & Type II b & NO \\
\hline Ceratophrys & Full epicoracoid overlap; 1:40 Rvp & NO & not defined & YES \\
\hline Litoria & Full epicoracoid overlap; 15:1 Lvp & $\begin{array}{l}\text { YES } \\
\text { (right) }\end{array}$ & not defined & YES \\
\hline Bufo & Full epicoracoid overlap; 10:1-30:1 Lvp & $\begin{array}{c}\text { YES } \\
\text { (left or right) }\end{array}$ & Type II a & YES \\
\hline
\end{tabular}

Lvp: left variant prevalence, Rvp: right variant prevalence

1. Classification following Emerson 1982. See text for explanation

2. See text for explanation of hindlimb use in righting responses.

parison shows that it has little importance for forelimb lateralization in anurans studied to date (Table 3, compare Bufo and Ceratophrys). Additional information on the pelvic girdle types in the species studied is addressed later in this review. As the skeletal asymmetry is not the main subject of the current review, further discussion is found in previous publications (Malashichev and Rogers, 2002; Kostylev and Malashichev, 2007). What should be stressed here is that the influence of the skeletal and behavioural asymmetries in any given species may interplay in different contexts.

\section{Locomotion}

Power for locomotion and gait performance is directed by the hindlimbs regardless of whether the locomotion is symmetrical (e.g., swimming, jumping) or utilizes alternate-limb performance (e.g., walking, climbing). It is therefore not surprising that in majority of cases we observe little asymmetry in the forelimb use revealed in only one particular behavioural test (e.g., snout-wiping test: see Table 2) and should expect a more pronounced asymmetry in the hindlimbs. As was hypothesised (Malashichev and Nikitina, 2002) and later shown (Malashichev, 2006a), motor lateralization for forelimb preferences in snout-wiping is positively correlated with the degree of asymmetric locomotion (i.e., alternate-limb walking and climbing) preferred in a given species. Indeed, the remarkable cases of lateralized forelimb preference are found in Bufo toads and tree frogs, which utilize alternate-limb gaits when walking and climbing, while the other anurans, especially symmetrical jumpers like true frogs has little if any asymmetry in forelimb use
(Malashichev, 2006a). Good examples of such symmetry are the semi-aquatic Bombina toads. They rarely walk, but usually use symmetrical swimming movements and, correspondingly, no lateralization of forelimb or hindlimb preferences have been found in this species. However an interesting question is why B. viridis shows only a weak forelimb preference and one which is against the general trend (Bisazza et al., 1997; Malashichev and Nikitina, 2002; Sovrano, 2007). The explanations given above might be added with another point to the list. This species of Bufo is the smallest in size among the three species of the genus studied so far and, especially in the younger age, prefers jumping (symmetrical locomotion) to walking (alternate-limb locomotion). This makes an important contrast to other two Bufo-species that definitely prefer walking to jumping. Bufo marinus makes a special case as it has not yet been studied as comprehensively for the snout-wiping responses as B. bufo (Bisazza et al., 1997) and B.viridis (Malashichev and Nikitina, 2002) to reveal clear forelimb preferences in any variant of the test, moreover has no wiping reflex (Gray, O'Reilly, and Nishikawa, 1997). As it is shown below, B. marinus is nonetheless highly lateralized for both hindlimb and forelimb use in righting response tasks.

\section{Lateralized use of the limbs in righting responses}

\section{RIGHTING RESPONSES AS AN ANALYTICAL TOOL}

The ability of an animal to right itself after being overturned has been described for a wide range of behavioural analyses - including the study of tool use in mol- 
luscs (Weldon and Hoffman, 1975), for measuring stress in chickens (Jones and Faure, 1981), and as an index of drug potency or chemical insult in various animal models, e.g., rats (Richter, Harris, and Hanford, 1982), mice (Markel, DeFries, and Johnson, 1995), adult frogs (Lapin, Oxenkrug, Osipova, and Uskova, 1970), tadpoles (Requintina, Oxenkrug, Yuwiler, and Oxenkrug, 1994; Firestone and Firestone, 1995; Downes and Courogen, 1996). Also termed the 'righting reflex', righting is a postural response distinct from locomotive behaviour such as swimming and walking, which require the operation of different sets of spinal reflexes, or central pattern generators (Grillner and Wallen, 1985; Stehouwer, 1986; Golubitsky, Stewart, Buono, and Collins, 1999). In other words, the overturned animal is not using swimming or walking reflexes in an effort to right itself. The righting response provides an alternative method with which to study limb preferences as it does not require fine motor abilities but comparatively gross motor patterns to initiate and complete the axial rotation of the overturned body. This is different to 'turning' behaviour, considered here as lateral rotation in the horizontal plane (e.g., C-starts in larval anurans: discussed above). In addition, righting responses are motor behaviours that do not require visual input to initiate or direct the motor activity (Klemm, 1977). For this reason, the study of limb preferences for righting provides a good basis with which to compare anuran species that chiefly use swimming or walking locomotive patterns.

The usefulness of the righting response to the study of limb preferences and voluntary motor patterns has been overlooked, even though there are some examples of lateralization for righting in the literature. Such observations have been noted with little further comment or explanation, e.g., studies of motor development in rat pups (Almli and Fisher, 1977). Possibly the oversight has been influenced by the general assumption of righting behaviour as a system of involuntary reflexes; albeit one that has multiple levels of complexity (Harvey, Ellis, and Tate, 1976; Klemm, 1977; Stehouwer, 1986; Pellis, Pellis, Morrissey, and Teitelbaum, 1989). To our knowledge such behaviors have not been used in other studies to measure limb left-right preferences in animals before the work of Bisazza and colleagues (Bisazza et al., 1996), in which B. marinus toads were repeatedly overturned in a waterbath (the aquatic-righting experiment).

\section{A COMPARATIVE SURVEY OF HORIZONTAL RIGHTING RESPONSES IN ANURANS}

As previously mentioned, the horizontal righting experiments have been primarily performed with toads of the genus Bufo (Robins et al., 1998). In a typical righting response a toad, being overturned on its back, first extends one of the hindlimbs and then pushes away from the substrate making a rapid flexion of the extended hindlimb. The upper body consequently rotates to complete the righting response (see also Fig. 9 and explanation in the figure caption). The righting response is completed either on the right side of the toad (left hindlimb use) or on the left side (right hindlimb use). All the three Bufo toad species studied (B. marinus, B. viridis, B. bufo) show a significant prevalence to right themselves to one side, thus revealing a significant footedness in righting response. Two species, namely B.marinus and B.bufo, appear to be right footed, while the third species (B.viridis) was found left footed (Robins et al., 1998). In B. viridis, the left hindlimb preference in horizontal righting response was supported in a later replicate study (Malashichev and Nikitina, 2002).

The latter work (Malashichev and Nikitina, 2002) further extended our knowledge of righting responses in anurans by addressing lateralization of hindlimbs in a different anuran species and genus. Fire-bellied toads, B. bombina, revealed no stable side-specific preference in the horizontal righting experiment (Malashichev and Nikitina, 2002). Individual B. bombina changed the degree and direction of lateralization in subsequent days of testing; moreover, they could use both hindlimbs in symmetrical longitudinal overturning the body to the upright position (occasionally and only in two individuals of 33 animals studied), although such trials were not scored and the trials immediately replaced. All these observations suggest that there is weak and unstable if any lateralization in the hindlimbs of fire-bellied toads.

Neither R. temporaria (Figs. 9A, 10A) nor R. lessonae (Fig. 10B) revealed any hindlimb lateralization for the horizontal righting experiments (Malashichev, 2006a). Thus, no behavioural test so far has revealed any lateralization of fore- or hindlimb use in a ranid species (cf. Tables 2 and 4). Interestingly, individual frogs of both species occasionally used both hindlimbs simultaneously in the course of righting, performing symmetrical backwards somersaults and pivoting on the snout and over the head. This symmetrical turning movement is similar to that noted previously in B. bombina (Malashichev and Nikitina, 2002). However individual fire-bellied toads rotated the body around the hips before landing to the belly, suggesting a difference between fire-bellied toads and true frogs in limb and trunk coordination.

In contrast, some species of tree frogs revealed strong lateralization of the hindlimbs in horizontal righting experiments. For example, Litoria latopalmata was found to be lateralized in this task revealing a population bias to pivot around the right side in $70 \%$ of trials (Rogers 2002). That is, the left hindlimb was preferentially used to push against the substrate. The same author has found, however, weak lateralization in another closely related species, L.caerulea. There were six animals with strong preference to use the left hindlimb in $70 \%$ of tri- 
A

(i)

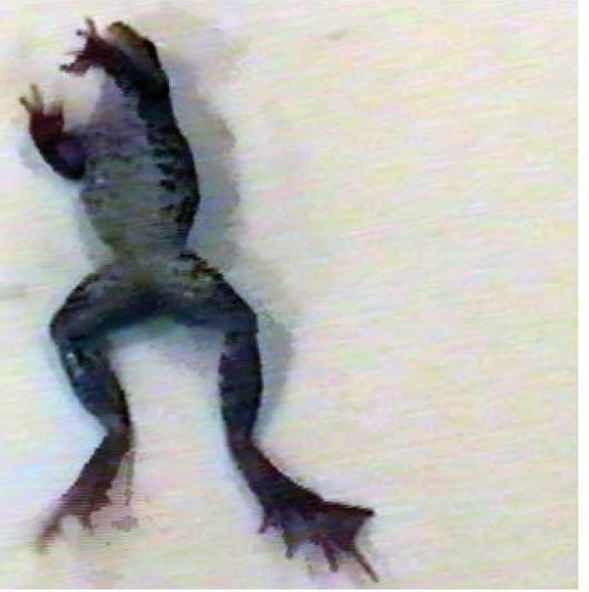

(ii)

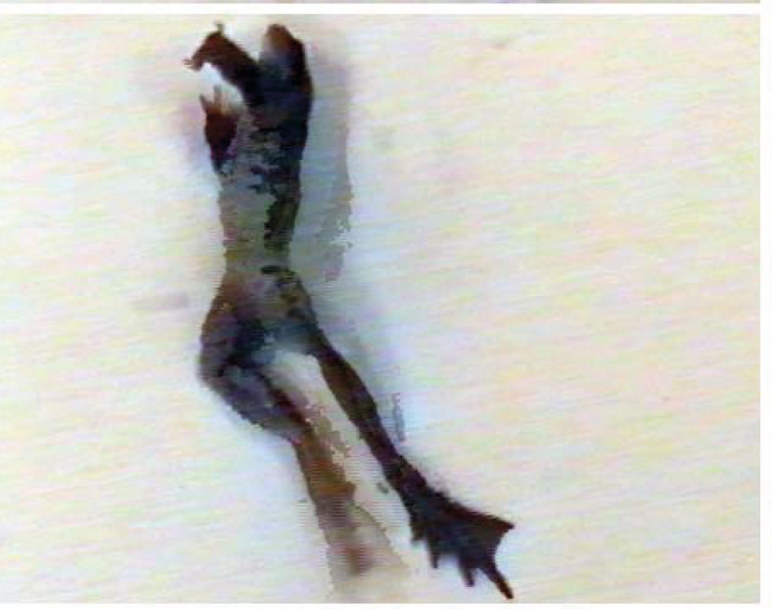

(iii)

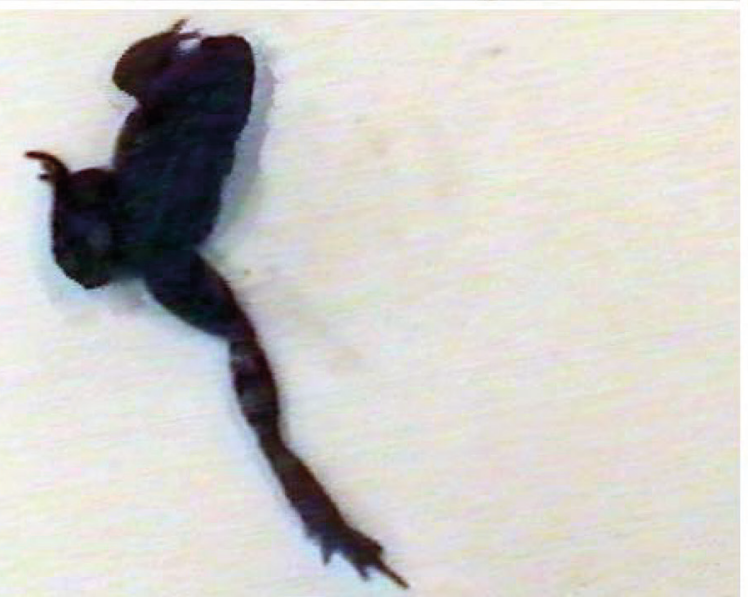

B

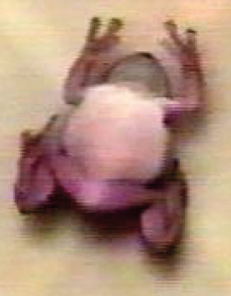

(i)

(ii)

(iii)

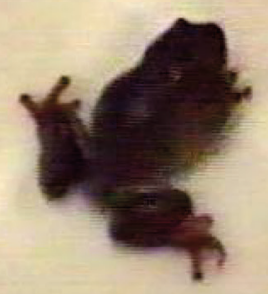

Fig. 9. The 'horizontal righting' experiment, when the hindlimb, which is used for turning for turning from overturned to the normal position is scored. The video-sequences show two different kind of turning techniques used by frogs: (A) pushing against the substrate with one hindlimb as exemplified in Rana temporaria and (B) overthrowing a hindlimb to the contralateral side to perform a momentum for rotation of the whole body as exemplified from experiment in Litoria caerulea.

als or more, while only two frogs were strongly rightfooted. Although statistically the left hindlimb preference here is not significant (see Table 4; Fig. 10C), a consequent study by Malashichev (2006) of another sample of L. caerulea has found a significant skew towards the same side with six left-footed and one right-footed individuals (Fig. 9B, 10D). The data from the two studies were pooled to show a significant population bias to- wards the use of the left hindlimb (Malashichev, 2006; Table 4).

The opposite lateralizations of hindlimb use in European spade-foot toads, P.fuscus, and Ornate horned frogs, C.ornata, for horizontal righting is also of note (Figs. 10E, F; Table 4; Malashichev, 2006). Spade-foot toads showed a significant tendency to use the right hindlimb when righting from the overturned position, 


\section{A. Rana temporaria}

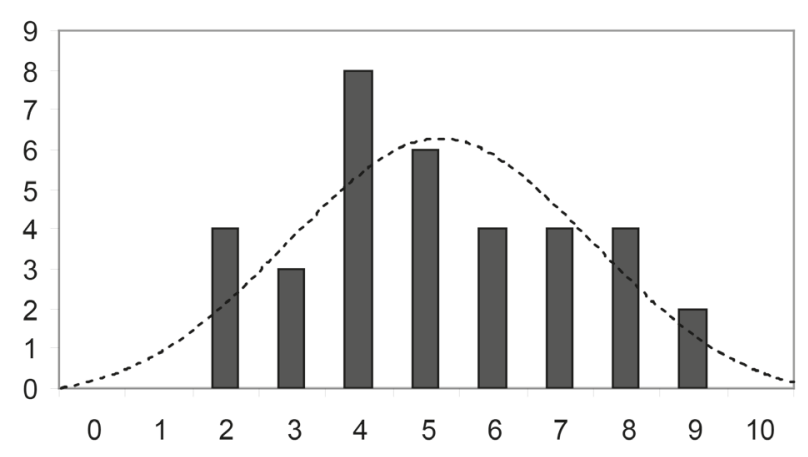

C. Litoria caerulea - Rogers, 2002

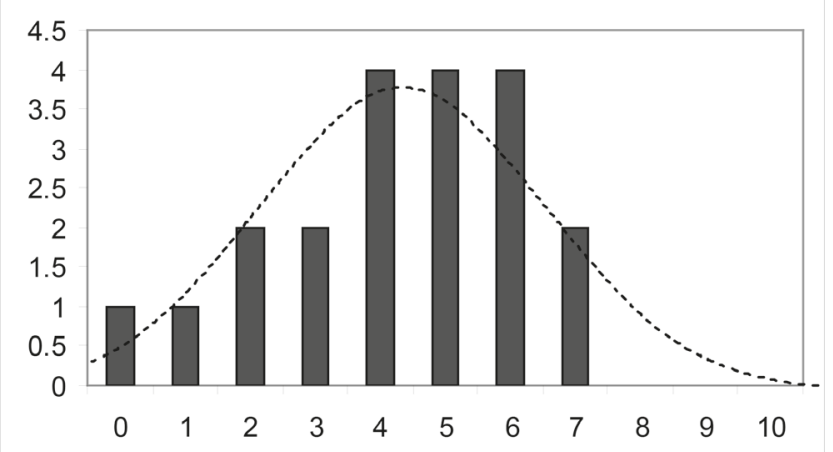

E. Pelobates fuscus

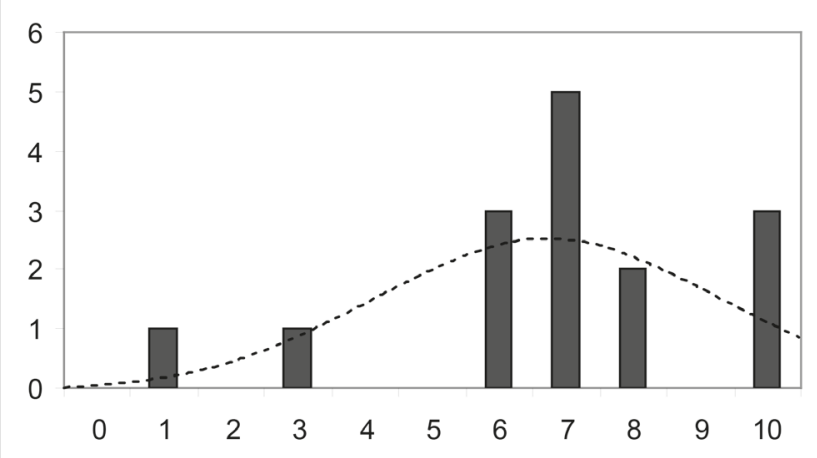

\section{B. Rana lessonae}

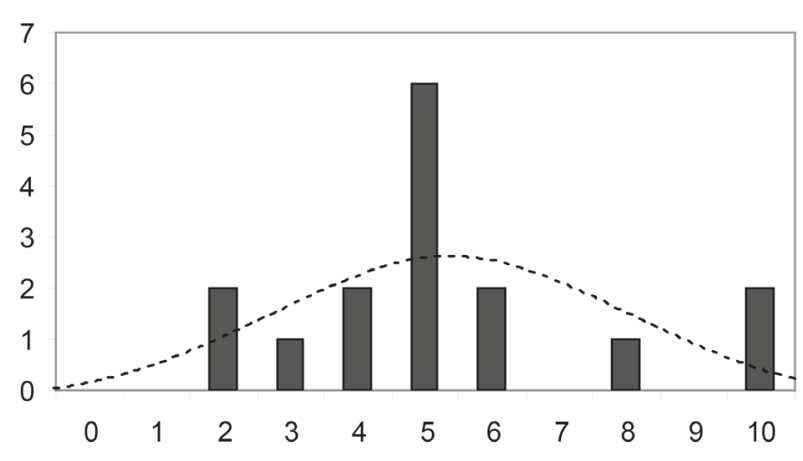

\section{Litoria caerulea}

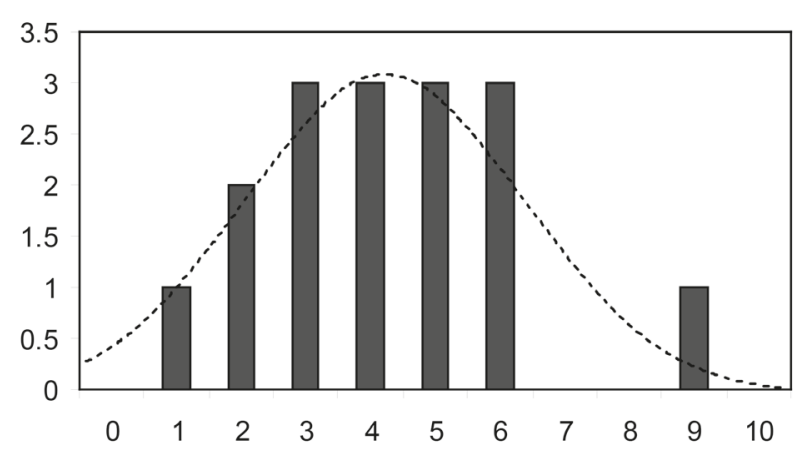

F. Ceratophrys ornata

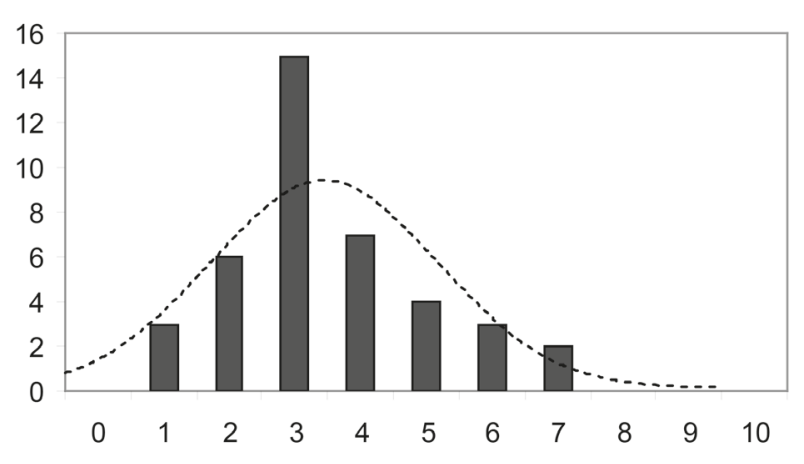

Fig. 10. Results of the horizontal righting experiment in different amphibian species. Data from Rogers, 2002 (C) and Malashichev, $2006 \mathrm{~b}$ (A, B, D-F).

while the significant bias towards the left hindlimb use was found in horned frogs. Interestingly, this comparative study reveals no phylogenetic trend in the degree or direction of hindlimb lateralization, but, as explained later, suggests correlation of the degree of hindlimb lateralization and the locomotive behaviours across anuran species.
FURTHER EXPERIMENTAL DESIGN TO STUDY RIGHTING RESPONSES IN B. MARINUS

Experiments of limb preferences in B.marinus righting responses have revealed some intriguing differences in aquatic righting (for forelimb preferences) and in horizontal righting (for hindlimb preferences). When tested 
Table 4. Horizontal righting responses in anurans given 10 consecutive trials

\begin{tabular}{|c|c|c|c|c|c|c|c|}
\hline & \multirow{2}{*}{ Population } & \multirow{2}{*}{$\mathbf{N}$} & \multicolumn{2}{|c|}{$\begin{array}{l}\text { No of animals with strong } \\
\text { hindlimb preference }(\geq 70 \%)\end{array}$} & \multirow{2}{*}{$\mathbf{G}$} & \multirow{2}{*}{$\mathbf{p}$} & \multirow{2}{*}{$\begin{array}{l}\text { Mean \% Right } \\
\text { (SEM) }\end{array}$} \\
\hline & & & Left & Right & & & \\
\hline P. fuscus & Tambov, Russia² & 15 & 2 & 10 & 5.81 & $<0.05$ & $68.7(6.3)$ \\
\hline R. temporaria & St. Petersburg, Russia² & 35 & 7 & 10 & 0.53 & NS & $51.71(3.8)$ \\
\hline R. lessonae & Pskov, Russia ${ }^{2}$ & 16 & 3 & 3 & 0 & NS & $53.12(5.9)$ \\
\hline C. ornata & captive breeding ${ }^{2}$ & 40 & 24 & 2 & 21.9 & 0.0001 & $35(2.4)$ \\
\hline \multirow[t]{3}{*}{ L. caerulea } & captive breeding1 & 20 & 6 & 2 & 2.09 & NS & $53.89(3.1)$ \\
\hline & captive breeding 2 & 16 & 6 & 1 & 3.96 & $<0.05$ & $42.5(4.96)$ \\
\hline & Total $^{3}$ & 36 & 12 & 3 & 5.77 & $<0.05$ & $42.5(3.2)$ \\
\hline
\end{tabular}

1. Data from Rogers 2002

2. Data from Malashichev, 2006a

3. The two data sets were concluded to be homogenous (heterogeneity chi-square test, Zar $1996: \chi_{1}{ }^{2}=0.0857, P=0.82, N S$ ) and were pooled

in the aquatic righting experiment (Fig. 11A-C) for three trials daily over six consecutive days, the toads were found to rotate their body to the right (using the right forelimb) in approximately $66 \%$ of the 18 trials provided; a result significantly different from chance (Bisazza et al., 1996, 1997). When later videotaped in a single series of five consecutive trials, the same toads were found to have a significant tendency to rotate rightwards in $80 \%$ of trials. Videotape analysis confirmed the use of the right forelimb in controlling the axial rotation of the body in $96 \%$ of cases. Another group of B. marinus toads were tested for righting from the horizontal in a videotaped experiment of five trials daily on two consecutive days, with hindlimb use scored for pushing against the horizontal surface to rotate the hips and body successfully to the righted position (Robins et al. 1996). On the first day of trials the toads revealed a significant preference to use the right hindlimb in $65 \%$ of cases, although a non-significant preference of $55 \%$ right-hindlimb use was recorded on the second day of trials. Together, these limb preference data for aquatic and horizontal righting experiments suggest that the number of successive trials provided to toads may be a mitigating factor in revealing lateralization. This may be due to direct influences, such as learning effects and improvements in motor coordination when righting, or to indirect influences, including non-specific effects of stress with repeated handling and inversion.

To test for inconsistencies or trends in apparent lateralization of limb use with experience of righting, a series of experiments were conducted of both aquatic and horizontal righting in the same groups of toads. Ten trials were provided to each toad in total, however these trials were conducted over one, two or three days (Robins and Rogers, 2002). In Experiment A, toads were provided three trials daily for 6 successive days (denoted as $A_{3,6}$ ) however for comparative purposes only the scores from the first 10 trials were used. Experiment B consisted of five consecutive trials daily on two successive days $\left(\mathrm{B}_{5,2}\right)$, with the data for the horizontal righting experiments published previously (Robins et al., 1998) and presented here across the 10 trials provided. Experiment $\mathrm{C}$ consisted on a single set of 10 trials only on a single day $\left(\mathrm{C}_{10,1}\right)$.

The results for the experiments are shown in Table 5 where a clear trend in the increase of right-forelimb preference for aquatic righting is shown. Percent right-forelimb use for aquatic righting showed a marked increase from close to $70 \%$ when the 10 trials were provided over three successive days $\left(A_{3,6}\right)$, to nearly $90 \%$ when the 10 trials were provided consecutively $\left(\mathrm{C}_{10,1}\right)$. The results from the former experiment approximate the strength of the original report of right-handedness in B. marinus for this task (Bisazza et al., 1996). In the latter experiment, although the data show the strongest degree of lateralization in limb preferences for non-human vertebrates, the similarity with the degree of right-handedness often reported in humans $(92 \%)$ is entirely coincidental. This is due in part to there being no "left-handed" toads in this experiment (right-forelimb preferences in individual toads were at least $70 \%$ ), although mainly due to the incompatibility of tasks for which handedness is reported in the respective species.

Table 5. Mean percent right-limb preferences (SEM) for righting responses in $B$. marinus

\begin{tabular}{l|c|c|c|c}
\hline Paradigm & Limb Scored & $\begin{array}{c}\mathbf{A}_{\mathbf{3}, \mathbf{6}} \\
n=\mathbf{1 3}\end{array}$ & $\begin{array}{c}\mathbf{B}_{\mathbf{5}, \mathbf{2}} \\
n=\mathbf{2 6}\end{array}$ & $\begin{array}{c}\mathbf{C}_{\mathbf{1 0 , 1}} \\
n=\mathbf{4 9}\end{array}$ \\
\hline Aquatic & Fore- & $69(3.5)^{\star *}$ & $79(2.7)^{\star *}$ & $89(1.9)^{\star *}$ \\
\hline Horizontal & Hind- & $53(6.1)$ & $59(3.3)^{\star}$ & $55(2.5)^{\star}$ \\
\hline
\end{tabular}

For details of the Experiments A, B, and C see text. * $p<0.05$, ** $p<0.001$ : Student's $t$-test (2-tailed). 

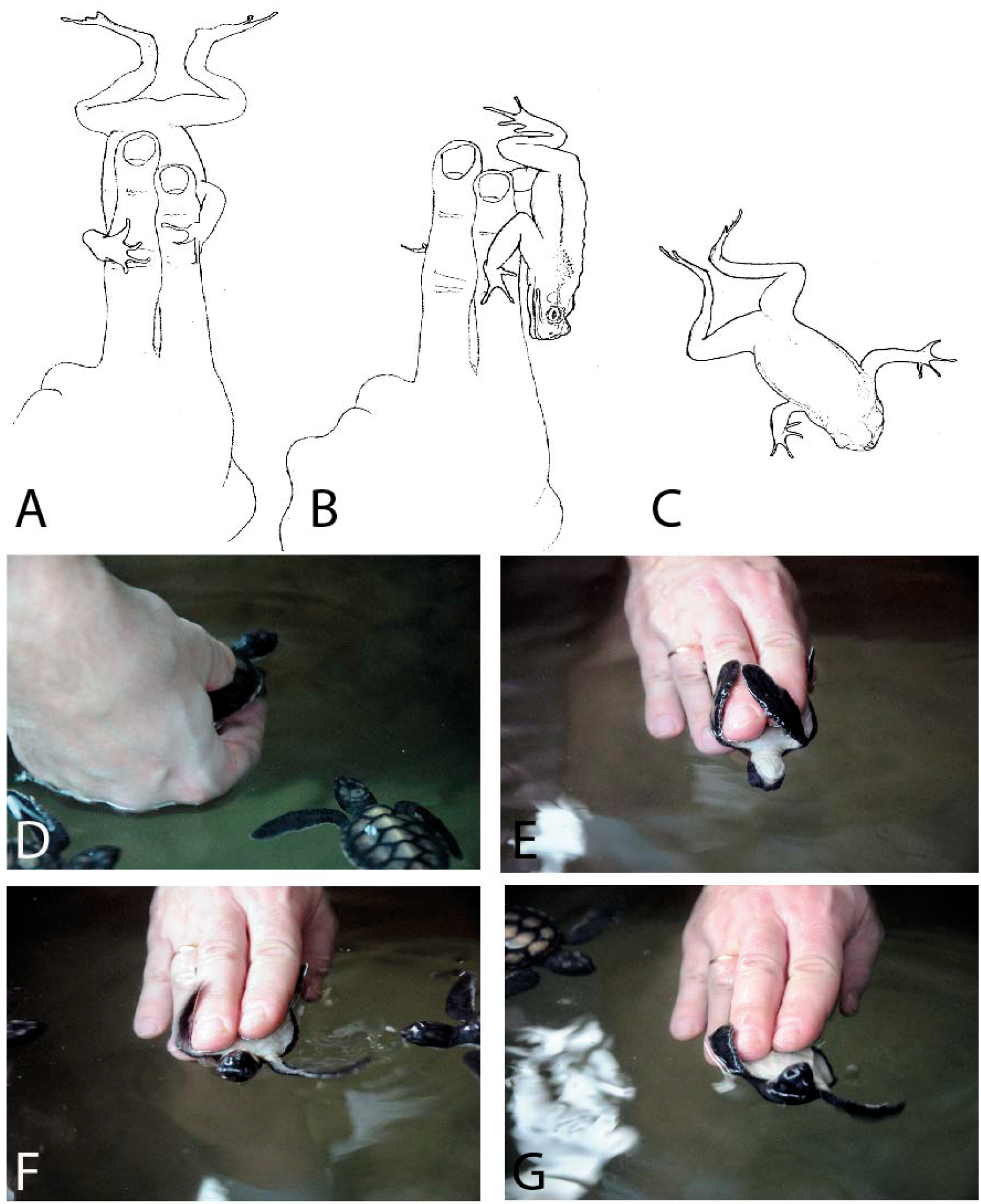

Fig. 11. A-C. The 'aquatic righting' experiment was devised to enable the toads with the opportunity to grasp a support with either forelimb to assist with the rotation of the body after being overturned. Briefly, the index finger and forefinger of the experimenter's hand (alternated in successive trials) provided such a support, the toad having been inverted over the rostro-caudal axis. During the overturning action the toads reflexively clasped the experimenter's two fingers while it was immersed in water and just below the surface so that the toad's body remained suspended and horizontal. The toad initiated the righting response by unclasping one forelimb and forcibly adducting the opposite forelimb so that axial rotation occurred whilst in continuous contact with the experimenter's fingers. D-G. Consequent phases of inversion-submersion (aquatic righting) test in a sea turtle, Chelonia mydas: the experimenter took a juvenile turtle swimming at thesurface of the water tank from behind (D), the turtle reflexively clasped theexperimenter fingers wih the flippers and in this position it is been overturned over its head and gently submerged under the water (E). The experimental animal then released one of the flippers without any influence from experimenter ( $F$ ) and turned over the corresponding side making a rotational stroke with the free flipper (G). This kind of test was only possible so far to apply to Green turtles of a certain age and only one time per animal (see text for further details). 
The data for the hindlimb preferences in the three horizontal righting experiments do not show the same trend as that found for the matched aquatic righting experiments (Table 5). Indeed, apart from a general tendency to prefer the right hindlimb overall when righting from the horizontal, significance was not reached in Experiment A and no obvious trend is apparent across all three experiments. In contrast to the clear increase in right-forelimb preference with increasing number of successive trials daily in the aquatic righting experiments, right-hindlimb preferences for horizontal righting experiments appear relatively weak and labile.

The data are insufficient to identify or suggest the effects of direct (e.g., training effects) or indirect factors (e.g., handling stressors) on the limb preference in either aquatic or horizontal righting experiments. Nonetheless, right-forelimb preference increases with the relative experience of the task, right-hindlimb preference does not. The clear distinction between the lateralization of forelimb and hindlimb use may be related to their respective roles in the righting tasks provided. In aquatic righting experiments the forelimbs (hands) are afforded a high degree of surface contact with the curved dorsal surface of the experimenter's fingers, from which the toads are initially suspended. By contrast, the degree of surface contact afforded by the hindlimbs (feet) on the horizontal plane is comparatively slight. Moreover, the manipulability of the B.marinus hand is greater than that of the foot. Thus, the degree of lateralization of limb preference may be related to maximizing the contact surface through which a force can be directed (i.e., forelimb adduction in aquatic righting, hindlimb dorsiflexion in horizontal righting) and this premise has been supported in a wider battery of righting experiments (Robins, 2002). The fact that the limbs of the right side of the body are preferred for such operations requiring strength is speculated below.

Interestingly, with aquatic righting experiment (or inversion-submersion test) was possible to assess motor lateralization not only in anuran species, but also in a marine turtle (Malashichev, unpublished observations). Here, testing of a group of 10-days old Green turtles (Chelonia mydas, $\mathrm{N}=36$, single attempt per individual, hands of experimenter were alternated) at Kosgoda Sea Turtle Conservation Project in December 2014 (Fig. 11D-G) revealed a group trend, although not significant, to release first the right flipper and roll over the right side underwater (13 left: 23 right, $z=-1.92$, p.0.1336, n.s.). After some of the turtles have been released, the test was repeated on the next day with a smaller group $(\mathrm{N}=27)$ with a resulting somewhat clearer, but still not significant, but approaching significance result (8 left : 19 right, $\mathrm{z}=-1.92, \mathrm{p}=0.0549$, n.s.). An influence of the experimenter hand to the proportion of left and right underwater rotations, was not noticed in either testing (Fisher's exact test, $\mathrm{p}=0.4887$ to 0.2087 , n.s.). These results indicate that underwater righting test can be applied not only to amphibians, but also to sea turtles (not at all stages, since green sea turtles only clutch around the experimenter fingers at age not exceeding two weeks, after which time this reflex disappears). More interestingly, the inversion-submersion test applied to Green turtles principally confirms a role of the fore-flippers in rotation: much like in righting on horizontal surface, turtles seem to preferentially use the same, the right, fore-flipper to make a stroke in the water to rotate. This side coincide with the preferential rightside rotation found in this species at individual level in the horizontal righting test (Malashichev, 2016).

\section{PATTERNS OF MOTOR LATERALIZATION ACROSS ANURAN SPECIES}

The above comparative studies of lateralization in both fore- and hindlimbs allow us not only to briefly discuss the immediate consequences of that research work in context of the hindlimb use, but also to compare motor lateralization in both limb pairs and rethink the information in a broader context. Particularly, we aimed here to collect and evaluate all the information on motor patterns in anuran amphibians available to date to build a universal model, describing such patterns. This subsection clarifies some of the background details from all the previous data.

\section{A. Interrelationships between forelimb and hindlimb preferences}

Only few studies of motor lateralization in anurans addressed the question of interrelationship of lateralization in fore- and hindlimb use across tasks (Malashichev, $2002,2006 a)$. In the following discussion, forelimb preferences for snout-wiping and hindlimb preferences for horizontal righting are therefore contrasted. Although the correlation between the fore- and hindlimb preference is not evident at the level of individuals, an interesting phenomenon is that in most of the studied species, even if the lateralization was weak and not significant, the direction of the asymmetry in the both fore- and hindlimb preferences usually coincided. Indeed, B. bufo and B. marinus toads are right handed and rightfooted species (Bisazza et al., 1996, 1997; Robins et al., 1998); B. viridis shows a significant tendency towards the left side in both fore- and hindlimbs (Robins et al., 1998; Malashichev and Nikitina, 2002; Sovrano, 2007). Horned frogs C.ornata also showed strong left footedness and although insignificant trend towards the use of the left forelimb. Even ambidextrous species like fire-bellied toads and true-frogs revealed slight shift towards one and the same side in their fore- and hindlimb preferences (Malashichev, 2002, 2006a). The apparent exclusion 
from the rule seems to be tree frogs, L. caerulea, showing lateralization of the fore- and hindlimbs of opposite direction (i.e., right handedness for snout-wiping and left footedness for horizontal righting), hence making a nice example of similarity of limb specialization for climbing as appeared in humans (Malashichev, 2006a). However the number of species studied to date is not enough for the final decision on whether this is the genuine pattern or a random effect. Another point is that the direction of motor lateralization in fore- and hindlimbs usually coincide within a species. However, this direction is not uniform across a variety of species that is some species demonstrate right biases, while some others demonstrate left biases in limb use. This inconsistency in motor lateralization of different species is still awaiting a clear explanation.

\section{B. Skeletal morphology of limbs and pelvic girdles}

Different length and weights of the long bones in the hindlimbs was not once the subject of investigation in respect to the existing asymmetry (Singh, 1971; Greer and Mills, 1997). However, in these works a correlation between the skeleton and behavioural asymmetry was only hypothesised, and not tested experimentally. Dill's (1977) work was the first to investigate a link between the skeletal asymmetry and motor lateralization. This researcher found that tree frogs, Hyla regilla, leap preferentially to the left to avoid a model predator (a looming ball) approaching from the frontal visual midline. This corresponded to the greater length in the long bones of the right hindlimb (i.e., right tibiofibula and right femur were longer than their left side counterparts in $83 \%$ and $67 \%$ of cases, respectively). However, no significant correlation was found between the relative asymmetry of the hindlimbs and the leaping preferences of individual frogs (Dill, 1977).

However, in a later study (Lippolis, Bisazza, Rogers, and Vallortigara, 2002) it was found that in three $B u f o$-species escape jumps usually directed to the right in the view of a model predator, generally suggesting a visual, not the motor origin of this lateralization. This bias was significant when the model predator was presented laterally (from the left, thus suggesting the right-hemisphere processing of the visual information). In contrast to the previous work on Hyla (Dill, 1977), experiments on Bufo-species (Lippolis, Bisazza, Rogers, and Vallortigara, 2002) did not show significant deviation from random in escape jumps of toads faced with a frontally-presented predator model. As noted elsewhere (Malashichev and Wassersug, 2004), this makes a contrast between the two discussed papers and, therefore, the visual lateralization examined in details by Lippolis and co-authors (2002) cannot fully explain the findings by Dill (1977). It is very probable, that the latter author measured simultaneously both visual lateralization and motor lateralization, and unfortunately, the role of each factor in his study cannot be evaluated now, post factum. However, it may also have some correlates with Dill's work, which was the first to suggest motor lateralization in Hyla regilla. If it is so, it supports later findings of motor lateralization in Litoria species found in horizontal righting experiments. Nevertheless, the correlation between the skeletal structure and pattern of motor lateralization remained unclear.

A later work (Robins and Rogers, 2002) was also aimed to find a link between the skeletal asymmetry and behavioural lateralization in B. marinus. However, only forelimb handedness was assessed in this study (aquatic righting test) and thus it was not possible at that moment to correlate the asymmetry in the hindlimb long bones and the lateralized hindlimb use in this species. Notably, there was no any significant correlation found between any skeletal asymmetry in fore- or hindlimbs (or shoulder girdle, see above) and the measured motor lateralization. Furthermore, the weights and lengths of the individual long bones of the forelimbs and hindlimbs, and of the limbs themselves, revealed no population asymmetry that could account for the strong lateralization in forelimb use for aquatic righting.

Contrary to the shoulder girdle and long bones of the both limb pairs, the anuran pelvis possesses no striking asymmetry, which could directly affect one-side preferences in hindlimb use. However, the structure of the pelvic girdle differ from species to species allowing contrasting modes of movements (discussed in more details in the next subsection). Emerson (Emerson, 1982) suggested three general types of ilio-sacral articulation in anurans (Fig. 12). Type I is characterised by an external ligament running between contralateral ilia superficial to the dorsal back musculature, with no insertion on the sacrum. This feature of articulation Type I correlates with the widest among anurans sacral diapophyses. Type II pelvic structures are characterised by an internal ligament originating on the anterior portion of the ilium and inserting directly in sacral diapophyses, with the difference between subtypes IIa and IIb residing in the width and the place of insertion of the ligament into the sacrum (Emerson, 1979, 1982). Type IIa ilio-sacral articulation correlates with less expanded diapophyses, while type IIb even with cylindrical, not expanded at all transverse processes of the sacrum. The three types of anuran pelvic structures further differ one of another by the shape of articular sesamoids, the origin and insertion sites of ilio-lumbaris muscle, relative lengths of the ilia and transverse processes, as well as condition of the dorsal crest of the ilium (Emerson, 1979, 1982).

All the three described types of anuran vertebral-pelvic joint might be also characterised, what is 


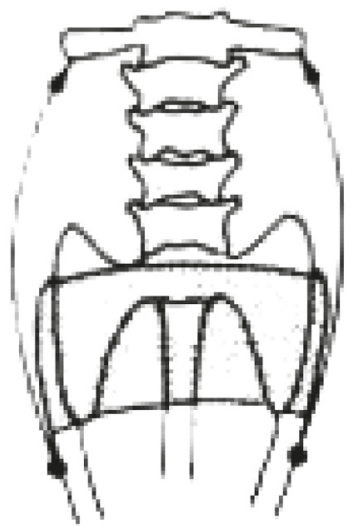

Type I

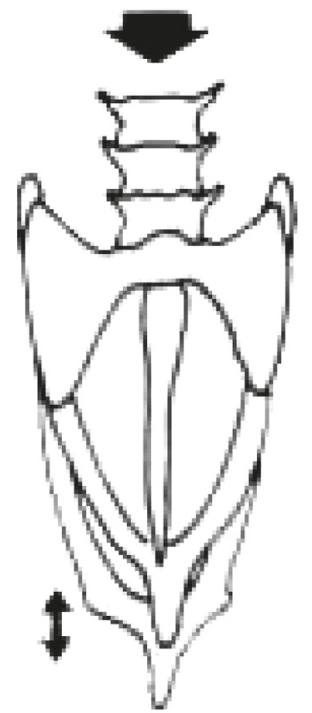

anteroposterior movements

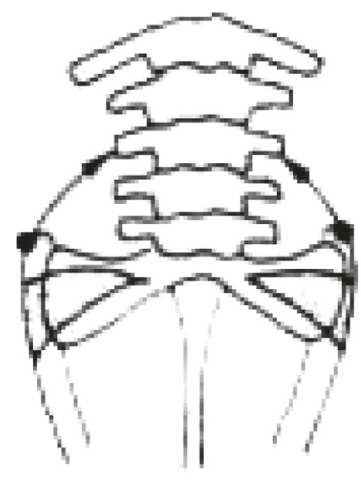

Type lla

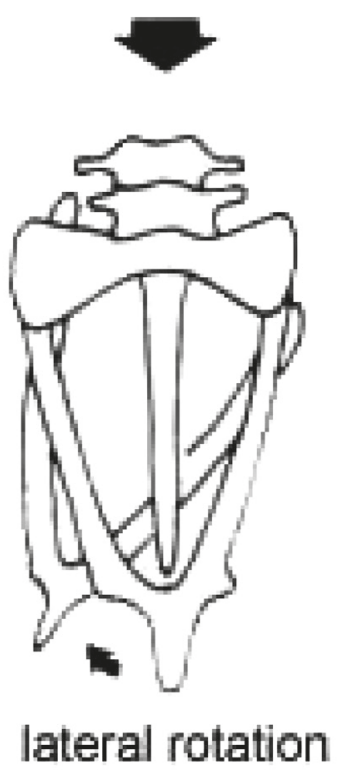

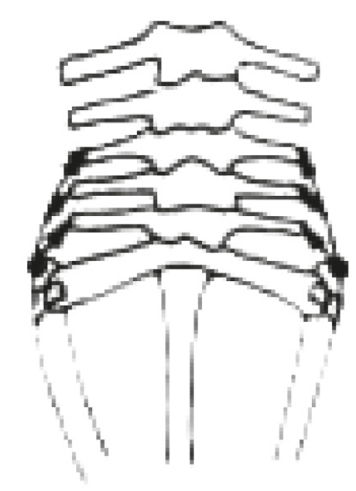

Type llb

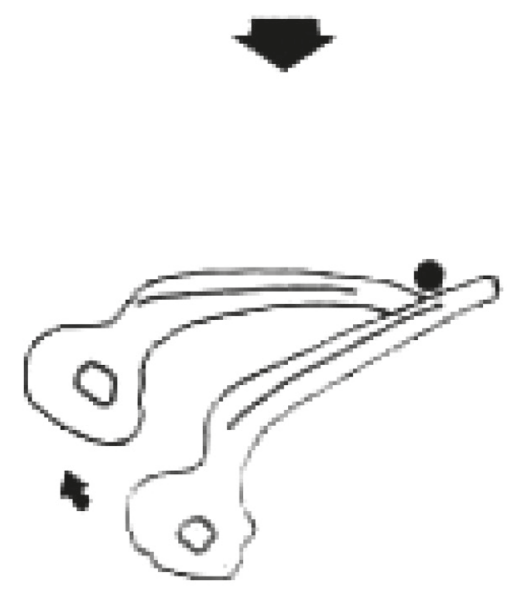

vertical rotation

Fig. 12. Three types of pelvic-sacral articulation after Emerson (1982). Articulation type I is characterized with expanded sacral transverse processes and development of muscular and ligamental pattern favorable for anteroposterior, longitudinal movements of the ilium about the sacrum, what is useful in swimming with simultaneous strokes with both hindlimbs. Articulation type Ila is characterized with the less expanded transverse processes of the sacrum and more flexible rotation of the pelvis, but mostly in horizontal plane, what is favorable for walking and climbing. Articulation type IIb is characterized by practically one point at the sacrum about which the pelvis rotates and allows first of all the rotation of the pelvis in the vertical plane. This type of articulation favorable to jumping, but is one of the most flexible, because it does not restrict other kinds of movements.

very interesting in the focus of our review, by a functional biomechanical features that are direct consequences of the articulation structure (Fig. 12). Type I articulation allows mostly longitudinal antero-posterior movements of the ilia along the extended sacral diapophyses, what is very effective in swimming, while restricts the lateral and especially vertical rotations of the ilia about the diapophyses and, subsequently, walking and jumping locomotion. Type IIa arrangement also forms a sliding joint, but with the predominant rotation in the horizontal plane, allowing effective lateral displacement of the ilium. Species with such an ilio-sacral articulation generally use walking, hopping and burrowing locomotion.
In the case of Type IIb of the pelvic structure the animal is faced to some difficulty in rotation of the pelvis about the sacral diapophyses in the horizontal plane with maximal vertical rotation. Type IIb species are jumpers and do not use walking locomotion (Emerson, 1982).

The general consideration of the lateralization in species possessing different types of ilio-sacral articulation seems to be problematic at the first sight, given the low number of species yet studied for which both the degree of motor lateralization and the anatomical pelvic structure are known. In particular some uncertainty arises from the fact that Litoria species may potentially have Type I or Type IIa, while Ceratophrys - Type IIa or 
IIb (Table 3, see also Table 1 in Emerson 1982). It is important, however, to underline the absence of lateralization of hindlimb use in Rana and Bombina (anurans restricted in the degree of possible lateral pelvic rotation) and the presence of significant lateralization in Bufo (a genus integrating many walking and running species). These data may indicate the existence of a link between the type of pelvic movements permitted, gait and lateralization of hindlimb use. Although this proposition is not absolutely apparent when dealing with pure mechanical considerations of the skeletal structure (i.e., at least $\mathrm{Pe}$ lobates seems to be an exclusion from the general rule, see Table 3), it finds further support in subsequent analysis of locomotion and other types of motor behaviour in anurans.

\section{Locomotion}

Collectively the results published (Robins et al., 1998; Malashichev and Nikitina, 2002; Rogers, 2002; Malashichev, 2006a) and considered in this review demonstrate a linkage between the one-side limb dominance and preference for alternative use of the left and right limbs during locomotion. Indeed, the anuran species that usually perform symmetrical locomotion (jumping or swimming) with both hindlimbs used simultaneously show little if any lateralization of fore- or hindlimb use (i.e., different species of Rana and Bombi$n a)$. On the contrary, the walking and climbing species show strong and consistent lateralization of the limb use as revealed by using varying experimental approaches (i.e., some Bufo-toads and different species of treefrogs). The Bufo-toads, which have been most closely investigated both in respect to variation of methods and to the number of species involved confirm this conclusion on the genus level. Indeed, B.bufo, and B. marinus which preferentially walk rather than jump, reveal a greater degree of lateralization than B. viridis, for which locomotion is biased more to jumping. Some evidence that walking is not a usual way of locomotion for Bufo marinus (Reilly, Montuelle, et al., 2015) and a lack of wiping reflex in this species (Gray, O'Reilly, and Nishikawa, 1997) may also partially explain some difficulties in registering lateralization at least in forelimbs. It would be therefore very interesting to estimate the degree of lateralization in such species, like B. calamita (matching in size to B. viridis) or California Toad, Anaxyrus (Bufo) boreas halophilus (matching in size to B.bufo) that both, in contrast to their counterparts rarely jump, but usually walk or run, or even climb rocks (Emerson, 1982; Walton, Peterson, and Bennett, 1994).

Considering anuran motor lateralization in a more broad spectrum of species, one's attention is attracted to water frogs, e.g. Xenopus laevis, using simultaneous strokes by hindlimbs when swimming, world-wide dis- tributed in laboratories, but unfortunately not properly studied in respect to lateralized behaviours, as well as alternate-limb swimming Leiopelma and Ascaphus (Abourachid and Green, 1999; Reilly, Essner, et al., 2015). It is predictable, that the former species is most probably an ambipreferent species, while the latter may have some degree of motor lateralization at least in the hindlimbs. Indeed, in X. laevis only 17 out of 42 frogs preferred to turn to the right or left arm of the Y-maze, without any distinct trend toward one of the sides at the group level found (Kostylev and Malashichev, 2007). In the same group of frogs it was shown that when surfacing to breathe, only 15 out of 42 frogs preferably dived rightwards or leftwards, and again a trend toward one side was also absent at the group level (Kostylev and Malashichev, 2007). Given the only study of X. laevis laterality is not fully comparable with other work on motor lateralization in anurans there is a need to a more detailed study of possible lateralized motor responses in this species. This task may be not as easy one, if one considers a very specific aquatic locomotion with certain constraints, as well as a lack of wiping, but presence of very specific scooping reflexes in the forelimbs (Gray, O'Reilly, and Nishikawa, 1997). On the other hand, it might occur that all aquatic frogs below Neobatrachia level will demonstrate lack of significant motor lateralization regardless of their preferred locomotion pattern as another theory predicts (Goree and Wassersug, 2001). A notion that it could be so, was given most recently in a student study of Ascaphus montanus (Sullivan, 2018), in which population level motor lateralization was not found in a set of tests including righting responses. Here, however, an insignificant tendency towards left side jumping took place, and given the relatively small sample size could actually mean a stronger bias. Nevertheless, even the low level of motor lateralization in this basal anuran does not reject the hypothesis on functional connection between the modes of locomotion (synchronous or asynchronous) to degree of motor lateralization in anurans in general. Instead, these observations give a hint that lateralization in anurans arose relatively late in neural evolution, only in Neobatrachian clade, where they manifest themselves in accordance with the mode of locomotion and degree of manipulative and other asynchronous activities of the limbs (see next section). This work also invites researchers to have a closer look at lateralization in other primitive and advanced families of anurans.

Although many experiments are yet to be conducted, it is becoming clear that the degree of limb lateralization is functionally somehow connected to the degree of alternation of limbs in a given species during locomotion (Malashichev, 2006a). It is likely therefore, that the more pronounced is the habit to use alternative locomotion, the greater is the functional asymmetry of the 
neural system to provide a basis for lateralization of motor responses; this conclusion was recently extrapolated beyond the amphibian class, e.g., turtles (Malashichev, 2016). One explanation for this is that the alternative contraction of the contralateral muscles during quadrupedal locomotion requires a more integrated neural control than the synchronous muscle contraction on the both sides of the body or that in certain species it acquires additional asymmetric neural substrates to better control asynchronous movements.

The latter conclusion is even more surprising due to the fact that hindlimb preferences for righting responses, believed to be not directly associated with locomotion (see above), are found to be lateralized in species favouring alternate-limb movements in locomotion (with exception of Ascaphus). Quadrupedal locomotion is controlled, at least in part, by a network of intraspinal neurons - central pattern generators (CPGs) - which generate a rhythmic output pattern and is suggested to be symmetric in structure (Golubitsky, Stewart, Buono, and Collins, 1999). Righting responses are not necessary directly involved in gait pattern generation. Nevertheless, a correlation between the mode of locomotion and the lateralized limb preference implies that either the neural network may include an element of asymmetry or, alternatively, that alternate-limb locomotion is directed by asymmetric neural centres other than spinal-level, central pattern generators (Malashichev, 2006a). Although our current knowledge of this issue is limited, some parallels found between spinal CPGs that control locomotion in lower vertebrates, and mammalian neocortex (Yuste et al. 2005) makes the hypothesis viable.

\section{Burrowing and luring behaviour}

The conclusions reached in the previous section might be additionally supported by observation of strong one-sided hindlimb preference found in two fossorial and ambush species, correspondingly, P.fuscus and C.ornata (Malashichev, 2006a). One of them, the spade-foot toad is a subterranean species. These toads hide during the light period of the day under the ground surface and go foraging at night. They are well known for their digging behaviour - alternating shuffling movements of the hindlimbs with expanded spade-like tubercles - to descend into the substrate. Ceratophrys-toads are ambush predators that usually watch for their prey with the hind body part partially buried in the substrate. This species also alternates hindlimb use when burrowing into the ground. Both anurans are ineffective jumpers with relatively short legs. It is not surprising therefore, that both $P$. fuscus and C.ornata were found to be strongly lateralized in their righting responses (Malashichev, 2006a).

Importantly, species of Ceratophrys genus also exhibit pedal luring behaviour, where only one hindlimb or, in extreme cases, both hindlimbs are used to attract prey (Murphy, 1976; Radcliffe et al., 1986). This means that not only alternate-locomotion per se, but any side movements which have alternative character may require lateralized neural control. On the other hand, the shuffling action in Pelobates when burrowing is not just an exact repetition of walking, which is restricted by the structure of ilio-sacral articulation Type I. Therefore, pelvic structure is, perhaps, not as important as the alternation of the left and right legs. In other words, a correlation between the pelvic structure and lateralized righting responses has no restrictive character: no action, hence no lateralization of the action. Rather, when a lateralized movement (e.g. walking) is restricted by the structural properties of the skeleton, but a different kind of movements (e.g. burrowing) exists, which uses a slightly different scheme of muscle contraction and simultaneously necessitate alternation in limb use, the motor lateralization can still be present in such a species. Thus motor preferences here are not a simple reflection of ilio-sacral articulation type, but represent a more complex coordinated organization between the skeleto-muscular structure, motor behaviour and its neural coordination.

Interestingly, both digging frogs use their right (Pelobates) or left (Ceratophrys) hindlimb approximately twice as frequently as the contralateral hindlimb (Malashichev, 2006a). They have a high proportion of strongly lateralized individuals in the population. This makes an interesting contrast to the lateralization of the forelimbs in the same species. In both species the lateralization of the forelimbs was not found in the snout-wiping test. This fact, however, does not mean that there is no such lateralization in the forelimbs, but just indicates that the lateralized function of the forelimbs that are rarely used in alternative fashion is not that pronounced, especially if compared to the hindlimbs that are used extremely asymmetrically in the everyday life of these toads.

\section{A GENERAL MODEL FOR DISTRIBUTION OF MOTOR LATERALIZATIONS IN ANURANS}

As we have already emphasised in the current section, there are many evidences to link motor lateralization in anuran amphibians with the overall structure and function of their bodies, which reflect adaptation to diverse environments, such as arboreal, terrestrial, underground and aquatic habitats. This adaptation is complex (Iordansky, 1990) in that it involves a number of structural and functional features, including musculo-skeletal anatomy, neural physiology and ecology of the species, where evolutionary change in one system necessitate changes in others or, at least, play a permissive influence on the appearance of limb lateralization. It is difficult to judge 


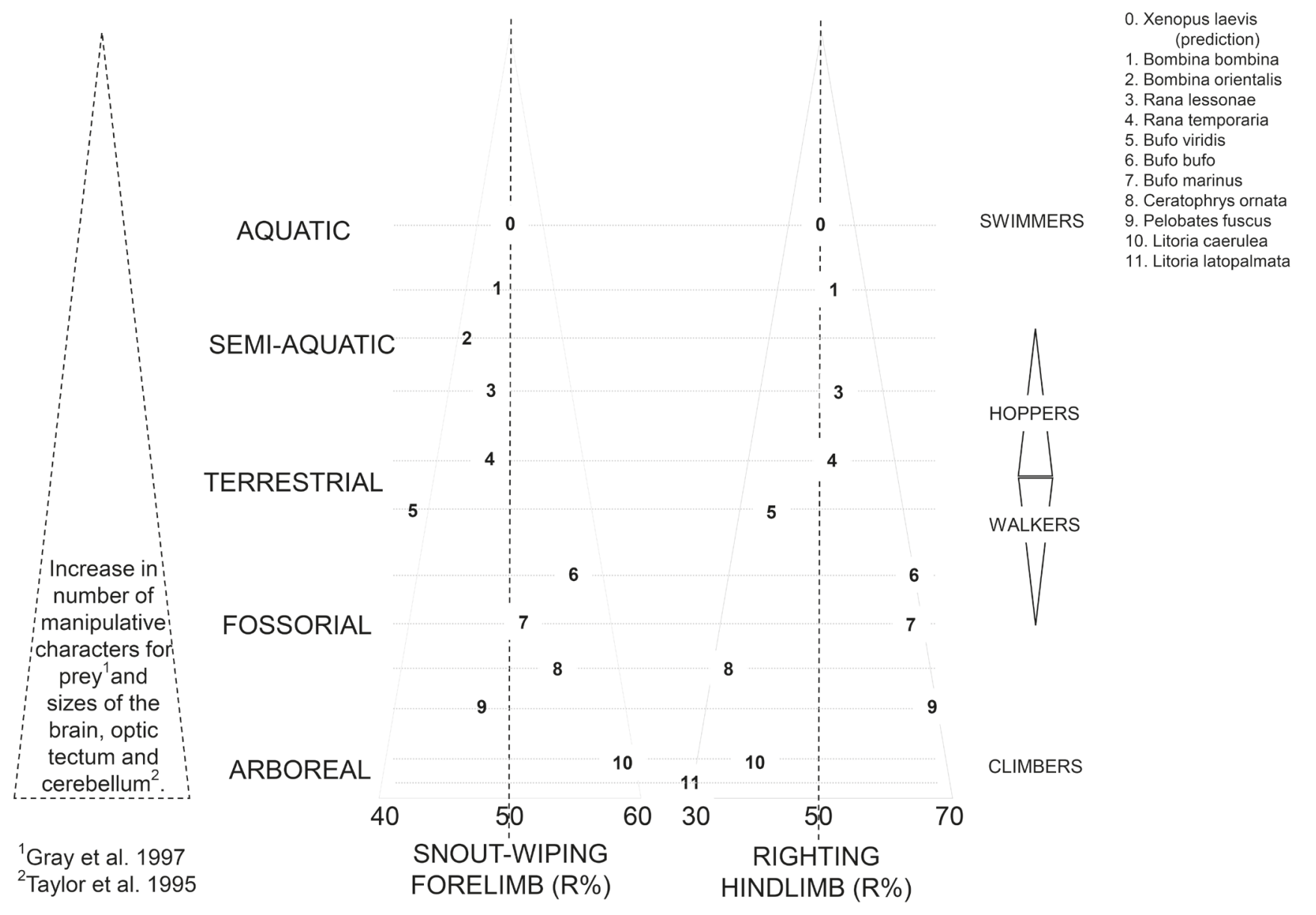

Fig. 13. A schematic representation of the correlations between lateralized motor responses in anurans and their eco-morphotypes. Our model predicts lack of any sign of motor lateralization in aquatic Xenopus laevis. The level of lateralization is very low and unstable in semi-aquatic Bombina-toads and Rana lessonae and even in fully terrestrial Rana temporaria and Bufo viridis. However, at the boundary between hoppers (Rana) and walkers (Bufo) the lateralization is starting to increase in a continuum, having a comparatively higher level in walking toads. Specialization of the fossorial species to digging with the help of hindlimbs has its reflection in increased preference in unilateral hindlimb use (Pelobates, Ceratophrys, Bufo). The highest percentage of both fore and hindlimb use we found in arboreal climbing anurans (tree frogs) which corresponds also with an increased manipulative ability (Gray, O'Reilly, and Nishikawa, 1997) and developed brain (Taylor, Nol, and Boire, 1995).

post-factum what kind of evolutionary novelty played the primary and most important role in this process in anurans, and this is perhaps the task for future research. Nevertheless, the system of found correlations between different aspects of this complex adaptation can be represented in a scheme (Fig. 13).

Perhaps, asymmetries of the skeleton structure is one of the primary correlates of motor lateralization. While the asymmetric structure of the shoulder girdle may directly influence lateralized behavioural response in some (especially aquatic) species, with weaker forelimbs, a greater effect appears correlated with the way in which the pelvic girdle articulates with the vertebral column. Depending on its type it allows or restricts certain kind of movements as to jumping or walking, and along with the overall body and limb proportions determines the spectrum of movements permissible for a species, and consequently, the utilization of the corresponding habitat type(s). When allowed by the anatomy the alter- nate-limb locomotion may take place in a species or may not, and if it does, then the motor response is usually lateralized (Malashichev, 2006a). For that several reasons are probable. First, the alternate movements with the contralateral limbs, regardless of whether they are due to walking or climbing, may require a more differential control from the neural system. Second, this initial lateralization and differentiation of the motor control can play a role of a feedback triggering mechanism for establishment of such specialised movement patterns, defined as adaptation to specific environments, as wrist rotation and grasping in tree frogs (Gray, O'Reilly, and Nishikawa, 1997) and digging and pedal luring of prey in some fossorial frogs. The specialization of other aspects of the brain structure and function follows or correlate with the lateralization of the neural system, or is determined directly during adaptation to the environment. Probably the best evidence for that are the data that the relative brain size and the relative size of brain regions correlate 
with the environmental specializations of species with the body size-corrected brains.

Although the visual and motor systems are conserved throughout the subclass Anura, adaptations to different habitats have led to changes in the various sizes of the anuran brain (Taylor, Nol, and Boire, 1995). Relative to body size, anuran species specialized for arboreal habitats have been found to possess larger brain sizes than anurans living in other habitats (i.e., fully aquatic, aquatic, fossorial and terrestrial anuran species). The enlargement of the cerebellum in arboreal anurans is the only brain area found to contribute significantly to the larger brain size overall. Enlargements in other brain areas, i.e., main olfactory bulb, accessory olfactory bulb, telencephalon, tectum, and diencephalon, mesencephalic tegmentum and medulla oblongata, measured together as the 'brain stem' are not significantly different between arboreal anurans and anurans from other habitats (Taylor, Nol, and Boire, 1995). An enlarged cerebellum in arboreal anurans could be expected as an adaptation to life in three-dimensional space, although it is surprising that the level of sensory and spatial integration demanded by such a habitat did not also result in an enlarged tectum or telencephalon (Taylor, Nol, and Boire, 1995). Nonetheless, subtle differences in brain structures relating to habitat adaptations may not only correspond with differences in behavioural patterns, but may also influence the degree of lateralization observed between anuran species from different habitats. If consider all these characters together, one can easily determine their apparently concordant change from aquatic to arboreal anurans. Such a general conclusion suggests an incremental perspective of evolution of brain functions in concert with other body structural and functional features during amphibian adaptation to diverse environments. This adaptation was accompanied by increased lateralization of the motor skills.

\section{Acknowledgements}

The authors thank Mikhail Kostylev for video footage of some experiments and video sequences of snout-wiping and righting-response tests on Figs. 6, 7 and 9, Richard Wassersug and Masamichi Yamashita for video-sequence on Fig. 1, Giorgio Vallortigara for photograph on Fig. 3A, Dunja Malashicheva for making photos for Fig. 9D-G. This work was supported by the Russian Science Foundation (Grant No. 14-1400284 to Y. M.).

\section{References}

Abourachid, A. and Green, D. M. 1999. Origins of the frogkick? Alternate-leg swimming in primitive frogs, families Leiopelmatidae and Ascaphidae. Journal of Herpetology 33:657-663. https://doi.org/10.2307/1565583

Adler, K. and Taylor, D. H. 1981. Toad orientation: variability of response and its relationship to individuality and environmental parameters. Journal of Comparative Physiology A: Neuroethology, Sensory, Neural, and Behavioral Physiology 144:45-51. https://doi.org/10.1007/BF00612796
Almli, C. R. and Fisher, R. S. 1977. Infant rats: sensorimotor ontogeny and effects of substantia nigra destruction. Brain Research Bulletin 2:425-459. https://doi. org/10.1016/0361-9230(77)90052-1

Andrew, R. J. and Dharmaretnam, M. 1991. A timetable of development; 166-176 in: Neural and Behavioural Plasticity: The use of the chick as a model, edited by Andrew, R.J. Oxford: Oxford University Press

Andrew, R. J., Tommasi, L., and Ford, N. 2000. Motor control by vision and the evolution of cerebral lateralization. Brain and Language 73:220-235. https://doi.org/10.1006/ brln.2000.2304

Bezgina, E. N., Moshkov, D. A., Nikitin, V.A., Savel'eva, L. N. and Uteshev, V.K. 1999. Morphogenesis of Mauthner neurons in Xenopus laevis tadpoles following early unilateral eye enucleation. Morphologiia 115(3):49-52.

Bianki, V. L. 1963. Asymmetry of electric reactions of the frog's brain in response to differentially positioned light sources. Journal of the Higher Neural Activity 13(6):1087-1095.

Bianki, V. L. 1981. Lateralization of functions in the animal brain. International Journal of Neuroscience 15(1-2):3747. https://doi.org/10.3109/00207458108985844

Bisazza, A., De Santi, A., Bonso, S., and Sovrano, V. A. 2002. Frogs and toads in front of a mirror: lateralization of response to social stimuli in five tadpole amphibians. Behavioural Brain Research 134(1-2):417-424. https://doi. org/10.1016/S0166-4328(02)00055-4

Bisazza, A., Cantalupo, C., Robins, A., Rogers, L.J., and Vallortigara, G. 1996. Right-pawedness in toads. Nature 379:408. https://doi.org/10.1038/379408a0

Bisazza, A., Cantalupo, C., Robins, A., Rogers, L. J., and Vallortigara, G. 1997. Pawedness and motor asymmetries in toads. Laterality 2:49-64. https://doi.org/10.1080/713754252

Blight, A. R. 1978. Golgi-staining of "primary" and "secondary" motoneurons in thedeveloping spinal cord of an amphibian. Journal of Comparative Neurology 180:679-690. https://doi.org/10.1002/cne.901800403

Borkhvardt, V. G. and Ivashintsova, E. B. 1995. Arciferal pectoral girdle of amphibians - an instrument for recognizing right- and left-handedness? Russian Journal of Herpetology 2:34-35.

Borkin, L. J., Litvinchuk, S. N., Rosanov, J. M., and Milto, K. D. 2001. Cryptic speciation in Pelobates fuscus (Anura, Pelobatidae): evidence from DNA flow cytometry. Amphibia-Reptilia 22:387-396. https://doi.org/10.1163/15685380152770354

Brácha, V., Zhuravin, I. A., and Bures, J. 1990. The reaching reaction in the rat: a part of the digging pattern? Behavioural Brain Research 36:53-64. https://doi.org/10.1016/01664328(90)90159-C

Briggs-Gonzalez, V.S. and Gonzalez, S. C. 2016. Lateralized turning biases in two neotropical tadpoles. Ethology 122:582-587. https://doi.org/10.1111/eth.12503

Canfield, J. G. 2003. Temporal constraints on visually directed C-start responses: Behavioral and physiological correlates. Brain, Behaviour and Evolution 61:148-158. https:// doi.org/10.1159/000069751

Casey, M. B. and Lickliter, R. 1998. Prenatal visual experience influences the development of turning bias in bobwhite quail chicks (Colinus virginianus). Neuropsychologia 33:1637-1646. https://doi.org/10.1002/(SICI)10982302(199805)32:4<327::AID-DEV7>3.0.CO;2-P

Dadda, M. 2005. Social aggregation and lateralised response to social stimuli in tadpoles (Bufo bufo): Influence of developmental stage. Laterality 10(4):345-352. https://doi. org/10.1080/13576500442000139

Dill, L. M. 1977. 'Handedness' in the pacific tree frog (Hyla regilla). Canadian Journal of Zoology 55:1926-1929. https:// doi.org/10.1139/z77-248 
Downes, H. and Courogen, P. M. 1996. Contrasting effects of anesthetics in tadpole bioassays. Journal of Pharmacology and Experimental Therapeutics 278:284-296.

Emerson, S. B. 1979. The ilio-sacral articulation in frogs: form and function. Biological Journal of the Linnean Society 11:153-168. https://doi.org/j.1095-8312.1979.tb00032.x

Emerson, S. B. 1982. Frog postcranial morphology: identification of a functional complex. Copeia 1982:603-613. https://doi.org/10.2307/1444660

Ewert, J.-P. 1980. Functional areas in the visual system of vertebrates: comparative aspects; 129-146 in: Neuro-Ethology, edited by Ewert, J.-P. Berlin: Springer-Verlag. https:// doi.org/10.1007/978-3-642-67500-3_5

Fernand, R. D. 1987. More than meets the eye. Behavioral and Brain Science 10:378-379. https://doi.org/10.1017/ S0140525X00023244

Fetcho, J. R. 1990. Morphological variability, segmental relationship, and functional role of a class of commissural interneurons in the spinal cord of goldfish. The Journal of Comparative Neurology 299(3):283-298. https://doi. org/10.1002/cne.902990303

Fetcho, J.R. 1991. Spinal network of the Mauthner cell. Brain, Behaviour and Evolution 37:298-316. https://doi. org/10.1159/000114367

Fetcho, J. R. 1992. Excitation of motoneurons by the Mauthner axon in goldfish: complexities in a "simple" reticulospinal pathway. Journal of Neurophysiology 67:1574-1586. https://doi.org/10.1152/jn.1992.67.6.1574

Fetcho, J. R. and Faber, D. S. 1988. Identification of motoneurons and interneurons in the spinal network for escapes initiated by the Mauthner cell in goldfish. Journal of Neuroscience 8:4192-4213. https://doi.org/10.1523/JNEURO$\mathrm{SCl} .08-11-04192.1988$

Firestone, S. and Firestone, L. L. 1995. Staurosporine, a protein kinase inhibitor, increases the intoxicating potenties of ethanol and other n-alkanols in Rana pipiens tadpoles. Alcoholism: Clinical and Experimental Research 19:416-419. https://doi.org/10.1111/j.1530-0277.1995. tb01524.x

Gaillard, F. 1990. Visual units in the central nervous system of the frog. Comparative Biochemistry and Physiology, A 96:357371. https://doi.org/10.1016/0300-9629(90)90097-C

Giljov, A., Karenina, K., and Malashichev, Y. 2011. History of the study of motor lateralization in birds. The Russian Journal of Ornithology 20(664):1151-1165.

Giljov, A., Karenina, K., Ingram, J., and Malashichev, Y. 2015. Parallel emergence of true handedness in the evolution of marsupials and placentals. Current Biology 25(14):18781884. https://doi.org/10.1016/j.cub.2015.05.043

Golubitsky, M., Stewart, I., Buono, P.-L., and Collins, J.J. 1999. Symmetry in locomotor central pattern generators and animal gaits. Nature 401:693-695. https://doi. org/10.1038/44416

Goree, B. and Wassersug, R.J. 2001. Are archeobatrachian anurans ambidextrous? - Assessing handedness in Bombina orientalis. Journal of Herpetology 35(4):538-541. https://doi.org/10.2307/1565980

Gosner, K. L. 1960. A simplified table for staging anuran embryos and larvae with notes on identification. Herpetologica 16:183-190.

Gray, L. A., O'Reilly,J. C., and Nishikawa, K. 1997. Evolution of forelimb movement patterns for prey manipulation in anurans. Journal of Experimental Zoology 277:417-424. https://doi. org/10.1002/(SICI)1097-010X(19970415)277:6<417::AIDJEZ1>3.0.CO;2-R

Greer, A. E. and Mills, A. C. 1997. Directional asymmetry in the amphibian pectoral girdle: additional data and a brief overview. Journal of Herpetology 31:594-596. https://doi. org/10.2307/1565619

Grillner, S. and Wallen, P. 1985. Central pattern generators for locomotion, with special reference to vertebrates. Annual Review of Neuroscience 8:233-261. https://doi. org/10.1146/annurev.ne.08.030185.001313

Harris, L. J. 1989. Footedness in parrots: Three centuries of research, theory, and mere surmise. Canadian Journal of Psychology / Revue canadienne de psychologie 43(3):369396. https://doi.org/10.1037/h0084228

Harvey, C. B., Ellis, C., and Tate, M. 1976. Inhibition of the righting reflex in the common bullfrog (Rana catespbeiana) employing an operant-avoidance procedure. Bulletin of the Psychonomic Society 7:57-58. https://doi. org/10.3758/BF03337120

Hughes, A. 1976. Metamorphic changes in the brain and spinal cord; 856-863. in: Frog Neurobiology, edited by Llinas, R. and Precht, W. Berlin: Springer-Verlag. https:// doi.org/10.1007/978-3-642-66316-1_30

Ingle, D.J. 1976. The visual system; 421-441 in: Physiology of the Amphibians, edited by Lofts, B. New York: Academic Press

Iordansky, N. N. 1990. Evolution of complex adaptations: jaw apparatus of amphibians and reptiles. Moscow: Nauka

Izvekov, E. I., Pavlova, V.V., Ognevaja, E. M., Nepomnyashchikh, V. A., and Malashichev, Y. B. 2018. Pattern of lateralized behaviors in a caudate amphibian, Ambystoma mexicanum. Russian Journal of Herpetology 25(1):31-42.

Jones, R. B. and Faure, J. M. 1981. Sex and strain comparisons of tonic immobility ("righting time") in the domestic fowl and the effects of various methods of induction. Behavioural Processes 6:47-55. https://doi.org/10.1016/03766357(81)90015-2

Klemm, W. R. 1977. Identity of sensory and motor systems that are critical to the immobility reflex (animal hypnosis). Psychological Record 27:145-159. https://doi. org/10.1002/jnr.490020108

Kostylev, M. A. and Malashichev, Y. 2007. Correlation of the shoulder girdle asymmetry with the limb skeleton asymmetry in Xenopus laevis. Doklady Biological Sciences 416(1):374-376. https://doi.org/10.1134/ S0012496607050146

Lapin, I.P., Oxenkrug, G. F., Osipova, S. V., and Uskova, N. V. 1970. The frog as a subject for screening thymoleptic drugs. Journal of Pharmacy and Pharmacology 22(10):781782. https://doi.org/10.1111/j.2042-7158.1970.tb08429.x

Lippolis, G., Bisazza, A., Rogers, L. J., and Vallortigara, G. 2002. Lateralization of predator avoidance responses in three species of toads. Laterality 7(2):163-183. https://doi. org/10.1080/13576500143000221

Malashichev, Y.B. 2002. Asymmetries in amphibians: A review of morphology and behaviour. Laterality 7(3):197217. https://doi.org/10.1080/13576500244000030

Malashichev, Y. B. 2006a. One-sided limb preference is linked to alternating-limb locomotion in anuran amphibians. Journal of Comparative Psychology 120(4):401-410. https://doi.org/10.1037/0735-7036.120.4.401

Malashichev, Y.B. 2006b. Is there a link between visceral and neurobehavioral asymmetries in development and evolution?; 33-44 in: Behavioral and Morphological Asymmetries in Veretbrates, edited by Malashichev, Y. B. and Deckel, W. Georgetown, TX: Landes Bioscience

Malashichev, Y.B. 2016. Asymmetry of righting reflexes in sea turtles and its behavioral correlates. Physiology and Behavior 157:1-8. https://doi.org/10.1016/j.physbeh.2016.01.001

Malashichev, Y. B. and Nikitina, N. G. 2002. Preferential limb use in relation to epicoracoid overlap in the shoul- 
der girdle of toads. Laterality 7(1):1-18. https://doi. org/10.1080/13576500143000032

Malashichev, Y.B. and Rogers, L.J. 2002. Behavioural and Morphological Asymmetries in Amphibians and Reptiles: Psychology Press Ltd.

Malashichev, Y. B. and Wassersug, R. J. 2004. Left and right in the amphibian world: which way to develop and where to turn? BioEssays 26(5):512-522. https://doi. org/10.1002/bies.20036

Markel, P. D., DeFries, J. C., and Johnson, T.E. 1995. Use of repeated measures in an analysis of ethanol-induced loss of righting reflex in inbred long-sleep and short-sleep mice. Alcoholism Clinical and Experimental Research 19:299-304. https://doi.org/10.1111/j.1530-0277.1995.tb01506.x

Mason, A. M., Wolfe, L. D., and Johnson, J. C. 1995. Hand preference in the sifaka (Propithecus verreauxi coquereli) during feeding in captivity. Primates 36:275-280. https://doi. org/10.1007/BF02381353

McGrew, W. C. and Marchant, L. F. 1992. Chimpanzees, tools, and termites: hand preference of handedness? Current Anthropology 33:114-119. https://doi.org/10.1086/204041

Mead, L. A. and Hampson, E. 1996. A sex difference in turning bias in humans. Behavioural Brain Research 78:73-79. https://doi.org/10.1016/0166-4328(95)00233-2

Murphy, J. B. 1976. Pedal luring in the leptodactylid frog, Ceratophrys calcarata Boulenger. Herpetologica 32(3):339341.

Naitoh, T. and Wassersug, R. J. 1996. Why are toads right-handed? Nature 380:30-31. https://doi.org/10.1038/380030b0

Nekaris, K.A.I. and Tab Rasmussen, D. 2003. Diet and feeding behavior of mysore slender lorises. International Journal of Primatology 24(1):33-46. https://doi. org/10.1023/A:1021442411455

Nordlander, R. H., Baden, S.T., and Ryba, T. 1985. Development of early brainstem projections to the tail spinal cord of Xenopus. Journal of Comparative Neurology 231:519-529. https://doi.org/10.1002/cne.902310409

Oseen, K. L., Newhook, L. K.D., and Wassersug, R.J. 2001. Turning bias in Woodfrog (Rana sylvatica) tadpoles. Herpetologica 57(4):432-437.

Pellis, S. M., Pellis, V.C., Morrissey, T.K., and Teitelbaum, P. 1989. Visual modulation of vestibularly-triggered air-righting in the rat. Behavioural Brain Research 74:207211. https://doi.org/10.1016/S0166-4328(89)80004-X

Radcliffe, C.W., Chiszar, D., Estep, K., Murphy, J. B., and Smith, H. M. 1986. Observations on pedal luring and pedal movements in leptodactylid frogs. Journal of Herpetology 20:300-306. https://doi.org/10.2307/1564496

Reilly, S. M., Essner, R., Wren, S., Easton, L., and Bishop, P.J. 2015. Movement patterns in leiopelmatid frogs: insights into the locomotor repertoire of basal anurans. Behavioural Processes 121:43-53. https://doi.org/10.1016/j.beproc.2015.10.001

Reilly, S.M., Montuelle, S.J., Schmidt, A., Naylor, E., Jorgensen, M. E., Halsey, L. G., and Essner, R. J. 2015. Conquering the world in leaps and bounds: hopping locomotion in toads is actually bounding. Functional Ecology 29(10):13081316. https://doi.org/10.1111/1365-2435.12414

Requintina, P.J., Oxenkrug, G. F., Yuwiler, A., and Oxenkrug, A. G. 1994. Synergistic sedative effect of selective MAO-A, but no MAO-B, inhibitors and melatonin in frogs. Journal of Neural Transmission (Suppl) 41:141-144. https://doi. org/10.1007/978-3-7091-9324-2_19

Richter, J. A., Harris, P. S., and Hanford, P. V. 1982. Similar development of tolerance to barbital-induced inhibition of avoidance behavior and loss of righting reflex in rats. Pharmacology, Biochemistry and Behavior 16:467-471. https://doi.org/10.1016/0091-3057(82)90454-3
Robins, A. 2002. Visual ad motor lateralization in two anuran species, Bufo marinus and Litoria caerulea. Ph. D. Research Thesis, University of New England, Armidale, Australia.

Robins, A. and Rogers, L.J. 2002. Limb preference and skeletal asymmetry in the cane toad, Bufo marinus (Anura: Bufonidae). Laterality 7(3):261-275. https://doi. org/10.1080/13576500244000049

Robins, A., Lippolis, G., Bisazza, A., Vallortigara, G., and Rogers, L.J. 1998. Lateralized agonistic responses and hind-limb use in toads. Animal Behaviour 56(4):875-881. https://doi.org/10.1006/anbe.1998.0877

Rogers, L.J. 1991. Development of brain lateralization; 507535 in: Neural and behavioural plasticity: The use of the chick as a model, edited by Andrew, R. J. Oxford: Oxford University Press

Rogers, L.J. 2002. Lateralised brain function in anurans: comparison to lateralisation in other vertebrates. Laterality 7(3):219-239. https://doi. org/10.1080/13576500244000012

Rogers, L. J. and Workman, L. 1993. Footedness in birds. Animal Behaviour 45:409-411. https://doi.org/10.1006/ anbe.1993.1049

Rogers, L.J., Ward, J.P., and Stanford, D. 1994. Eye dominance in the small-eared bushbaby, Otolemur garnettii. Neuropsychologia 32(2):257-264. https://doi. org/10.1016/0028-3932(94)90011-6

Rutledge, R. and Hunt, G. R. 2004. Lateralized tool use in wild New Caledonian crows. Animal Behaviour 67:327-332. https://doi.org/10.1016/j.anbehav.2003.07.002

Singh, I. 1971. One-sided dominance in the limbs of rabbits and frogs, as evidenced by asymmetry in bone weight. Journal of Anatomy 109:271-275

Sovrano, V. A. 2007. A note on asymmetric use of the forelimbs during feeding in the European green toad (Bufo viridis). Laterality 12(5):458-463. https://doi. org/10.1080/13576500701479822

Stehouwer, D. J. 1986. Behavior of larval and juvenile bullfrogs (Rana catesbeiana) following chronic spinal transection. Behavioral and Neural Biology 45:120-134. https://doi. org/10.1016/S0163-1047(86)80011-5

Sullivan, R. A. 2018. Handedness is not linked to locomotion in a basal anuran (ProQuest No. 10808549). Master Thesis, Southern Illinois University, Edwardsville.

Taylor, G. M., Nol, E., and Boire, D. 1995. Brain regions and encephalization in anurans: adaptations or stability? Brain, Behaviour and Evolution 45:96-109. https://doi. org/10.1159/000113543

Tommasi, L. and Vallortigara, G. 1998. Footedness in binocular and monocular chicks. Laterality 4:89-95. https://doi. org/10.1080/713754325

Uziel, D., Lopesconceicao, M. C., Luiz, R. R., and Lent, R. 1996. Lateralization of rotational behavior in developing and adult hamsters. Behavioural Brain Research 75:169-177. https://doi.org/10.1016/0166-4328(96)00205-7

Uziel, D., Lopesconceicao, M. C., Simpson, D., and Lent, R. 1998. Ontogenesis of lateralized rotational behavior in hamsters - a time series study. Behavioural Brain Research 92:47-53. https://doi.org/10.1016/S01664328(97)00122-8

Vallortigara, G. and Bisazza, A. 2002. How ancient is brain lateralization?; 9-69 in: Comparative vertebrate lateralization, edited by Rogers, L. J. and Andrew, R. J. Cambridge: Cambridge University Press

Walton, B. M., Peterson, C. C., and Bennett, A. F. 1994. Is walking costly for anurans? The energetic cost of walking in the Northern toad Bufo boreas halophilus. Journal of Experimental Biology 197:165-178. 
Ward, J. P., Milliken, G. W., and Stafford, D. K. 1993. Patterns of lateralized behavior in prosimians; 43-74. in: Primate Laterality: Current Behavioral Evidence of Primate Asymmetries, edited by Ward, J. P. and Hopkins, W. D. New York: Springer Verlag. https://doi.org/10.1007/978-1-4612-4370-0_2

Wassersug, R.J. and Yamashita, M. 2002. Assessing and interpreting lateralized behaviours in anuran larvae. Laterality 7(3):241-260. https://doi.org/10.1080/13576500244000003

Wassersug, R. J., Naitoh, T., and Yamashita, M. 1999. Turning bias in tadpoles. Journal of Herpetology 33(4):543-548. https://doi.org/10.2307/1565570
Weldon, P.J. and Hoffman, D. L. 1975. Unique form of tool-using in two gastropod molluscs (Trochidae). Nature 256:720-721. https://doi.org/10.1038/256720a0

Will, U. 1986. Mauthner neurons survive metamorphosis in anurans: A comparative HRP study on the cytoarchitecture of Mauthner neurons in amphibians. The Journal of Comparative Neurology 244(1):111-120. https://doi. org/10.1002/cne.902440109

Will, U. 1991. Amphibian Mauthner cells. Brain, Behaviour and Evolution 37:317-332. https://doi. org/10.1159/000114368

Yamashita, M., Naitoh, T., and Wassersug, R. J. 2000. Startle response and turning bias in Microhyla tadpoles. Zoological Sceince 17:185-189. https://doi.org/10.2108/ zsj.17.185 